\title{
ARIMA Models for Predicting the End of COVID-19 Pandemic and the Risk of a Second Rebound
}

\section{Zohair}

Taibah University https://orcid.org/0000-0002-9594-4957

Elsayed ( $\nabla$ satlam@taibahu.edu.sa)

Taibah University https://orcid.org/0000-0002-4728-590X

\section{Ashraf Ewis}

Umm AlQura University

\section{Guesh Dagnew}

Dire Dawa University

\section{Ahmad Reda}

Taibah University

Ghada Elmarhomy

Taibah University

Mostafa A. Elhosseini

Taibah University

Aboul Ella Hassanien

Cairo University

Ibrahim Gad

Tanta University

\section{Research Article}

Keywords: COVID-19 Pandemic, Infection control, SARIMA, Prediction, Second Rebound, AIC, ARIMA Models.

Posted Date: June 15th, 2020

DOl: https://doi.org/10.21203/rs.3.rs-34702/v1

License: (1) (i) This work is licensed under a Creative Commons Attribution 4.0 International License. Read Full License 


\title{
ARIMA Models for Predicting the End of COVID-19 Pandemic and the Risk of a Second Rebound
}

\author{
Zohair Malki $^{\mathrm{a}}$, El-Sayed Atlam ${ }^{\mathrm{b}, \mathrm{a}}$, Ashraf Ewis ${ }^{\mathrm{c}, \mathrm{d}}$, Guesh Dagnew $^{\mathrm{e}}$, Ahmad Reda Alzighaibi ${ }^{\mathrm{a}}$, ELmarhomy Ghada $^{\mathrm{a}}$ \\ Mostafa A. Elhosseini ${ }^{\mathrm{f}, \mathrm{a}}$, Aboul Ella Hassanien ${ }^{\mathrm{g}}$, Ibrahim Gad ${ }^{\mathrm{a}}$ \\ ${ }^{a}$ College of Computer Science and Engineering, Taibah University, Yanbu, SAUDI ARABIA \\ ${ }^{b}$ Faculty of Science, Tanta University, Egypt. \\ ${ }^{c}$ Department of Public Health and Occupational Medicine, Faculty of Medicine, Minia University, El-Minia, Egypt. \\ ${ }^{d}$ Department of Public Health, Faculty of Health Sciences - AlQunfudah, Umm AlQura University, Meccah, SAUDI ARABIA \\ ${ }^{e}$ Department of Computer Science, Institute of Technology, Dire Dawa University, Ethiopia. \\ ${ }^{f}$ Mansoura University, Computers Engineering and Control Systems Department, Faculty of Engineering, Mansoura, Egypt. \\ ${ }^{g}$ Faculty of Computers and Artificial Intelligence Cairo University.
}

\begin{abstract}
Globally, many research works are going on to study the infectious nature of COVID-19 and every day we learn something new about it through the flooding of the huge data that are accumulating hourly rather than daily which instantly opens hot research topics for artificial intelligence researchers. However, the public's concern by now is to find answers for two questions; 1) when this COVID-19 pandemic will be over? and 2) After coming to its end, will COVID-19 return again in what is known as a second rebound of the pandemic?. This research developed a predictive model that can estimate the expected period of time that the virus can possibly stopped and the risk of a second rebound of COVID-19 pandemic. Therefore, this study considered SARIMA model to predict the spread of the virus on several selected countries and is used for pandemic life cycle and end date predictions. The study can be applied to predict the same for other countries as the nature of the virus is the same everywhere. The advantages of this study are that it helps the governments in making decisions and planning now for the future, reduces anxiety and prepares the mentality of people for the next phases of the pandemic. The most striking finding to emerge from this experimental and simulation study is that the proposed algorithm show that the expected COVID-19 infections for the top countries of highest number of confirmed case will slowdown in October, 2020. Moreover, our study forecasts that there may be a second rebound of the pandemic in a year time, if the current taken precautions are eased completely. We have to consider the uncertain nature of the current COVID-19 pandemic and the growing inter-connected and complex world, what are ultimately required are the flexibility, robustness and resilience to cope up the unexpected future events and scenarios.
\end{abstract}

Keywords: COVID-19 Pandemic, Infection control, SARIMA, Prediction, Second Rebound, AIC, ARIMA Models.

\section{Introduction}

On December $8^{\text {th }}, 2019$ a novel Corona Virus Disease (COVID-19), a member of the family of the Severe Acute Respiratory Syndrome Corona-virus-2 (SARSCoV-2) started to infect people in the city of Wuhan, China [1]. COVID-19 was declared as pandemic by world health organization (WHO) on March, 11th, 2020 and since then it invaded almost all countries in the world [2].

Essentially, COVID-19 is an infectious viral disease that is transmitted from human-to-human through droplets whether direct; during coughing, sneezing of the patient or the carrier of the disease or indirect; through getting in contact with the patient's saliva on close contact, shaking hands, using his personal articles or touching surfaces soaked with his droplets containing the virus. The virus finds its way into the human body through the mucus membranes of the mouth, nose and eyes $[2,3,4]$.

Clinical picture of the COVID-19 infected patients varies significantly, from being asymptomatic to having severe form of the disease. In most cases, high fever, cough, sore throat, general weakness, fatigue, and muscular pain are manifested in many patients. In the severe cases, pneumonia, acute respiratory distress syn- 
drome, micro-coagulopathies, sepsis and septic shock are highly manifested, and in many instances, it could lead to death. Reports show that clinical deterioration occurs rapidly, often during the second week of the course of the disease $[5,6]$. Patients with underlying medical conditions such as cardiovascular disease, diabetes, chronic respiratory disease, cancer and old-aged people are more likely to experience serious illness [7].

Since it has been first reported, the COVID-19 invaded 210 countries and territories around the world [8]. As for May, 3rd, 2020, in more or less a four month period, a total of 3,521,538 confirmed cases of COVID-19 were reported and its death toll showed about 250,072 deaths.

Many research works are going on to study the infectious nature of COVID-19 and every day we learn something new about it through the flooding of the huge data that are accumulating hourly rather than daily [9]. However, by now, some information are known about COVID-19, its full characteristics are still unclear. One of the COVID-19 features is that it is able to change its nature very quickly due to its accelerated genetic mutations. Therefore, scientists are continuously performing observational studies just to establish facts about COVID-19 that will help in ending its pandemic. However, the viral genetic mutations increases the likelihood of having a second wave of the pandemic in future [9].

After recognizing the high rates of spread of COVID19 , the severity of cases and its related high death rates, the world rulers followed the advice of the WHO and took decisions of locking-down cities, banning local and international flights, restricting movements of millions and suspending schools, universities and business operations. Such decisions made the people to feel stressed, depressed and/or anxious, with variable degrees of psychological impacts. Moreover, with the long stay at home, the people are getting anxious and looking forward to return to their normal life, work and activities $[10,11]$.

The ARIMA and SARIMA models are common widely used statistical approaches for time-series analysis and forecasting. The non-seasonal ARIMA $(p, d, q)$ method is utilized to build the pure seasonal $\operatorname{SARIMA}(p, d, q) \times(P, D, Q)_{s}$ model. The public's concern by now is to find answers for two questions; 1) when this COVID-19 pandemic will be over? and 2) After coming to its end, will COVID-19 return again in what is known as a second rebound of the pandemic?. In this paper, using the the SARIMA model which is a common widely used statistical approach for stationary time-series forecasting, we will answer both questions on scientific basis of algorithmic modelling.
The main contributions of our research work includes:

- Expected COVID-19 infections of the confirmed case will slowdown in October 2020.

- A second rebound of the pandemic in a year time if the currently taken precautions are eased completely.

- To the best of our knowledge, there no previous work that uses the SARIMA model, hence we are contributing a unique model that predicts in the highest possible accuracy on predicting the end date of COVID-19 pandemic.

- Evaluate the ability of the SARIMA model for the prediction of the spread of COVID-19 pandemic using statistical visualization graphs such as normal distribution which makes our work better easily understandable to the readers.

- The predictive technique depends on the quality and density of the collected data of WHO.

- The predictive help the governments in making decisions and plan for the future, reduces anxiety and prepares the mentality of people for the next phases of the pandemic.

The aim of this study is to find the best prediction models for daily confirmed cases in countries with the highest number of confirmed cases in the world and to predict confirmed cases in order to have more readiness in healthcare systems so as to make forecasts of the confirmed cases in the next fifteen days.

This paper is organized as follows: Section 2 presents the related works. Section 4 introduces our new methodology and the proposed approaches. Section 5 presents the experimental observations. Section 5.2 explains our detailed discussion. Finally, the conclusions and possible future works are introduced in Section 6.

\section{Related work}

Lai et al. [12] studied the epidemic nature of COVID19 incidence in terms of daily cumulative index, mortality rate, and associative status of the countries health care resources and economy. With catastrophic outbreak of COVID-2019 globally, huge volume of data is generated instantly that opens hot research topic for machine learning and artificial intelligence researchers.

Jianxi Luo [13] provided a simple figure for each country to show the estimated pandemic life cycle together with the actual data or history to date, which 
in turn reveals the inflection point and ending phase. The predictions were started purely driven by personal curiosity regarding when COVID 19 will end. However, this paper need more update with more analyses and cases, as well as sharing of learning and reflections from this exercise and they did not use any mathematical model to predict.

Raj Dandekar and George Barbastathis [14] proposed a method to capture the current infected curve growth and predicts a halting of infection spread by 20 April 2020. This method has shown that reversing quarantine measures right at this time can lead to an exponential explosion in the infected case count, thus annulling the part played by all measures implemented in the US since mid-March 2020. However, the model uses only for a period of 1 month following the current US policy, that implies it has lack of sufficient data to predict correctly.

IHME COVID-19 health service utilization forecasting team, Christopher JL Murray [15] peaked daily deaths varies from March 30 through May 12 by state in the US and March 27 through May 4 by country in the EEA. They have estimated that through the end of July, there will be 60,308 (34,063-140,381) deaths from COVID-19 in the US and 143,088 (101,131-253,163) deaths in the EEA. Deaths from COVID-19 are estimated to drop below 0.3 per million between May 4 and June 29 by state in the US and between May 4 and July 13 by country in the EEA. Timing of the peak required for hospital resources requirements varies highly across states in the US and across regions of Europe. Interpretation: Apart from scoring a large number of deaths from COVID-19, the epidemic will place a load on health system resources well beyond the current capacity of hospitals in the US and EEA to manage, especially for ICU care and ventilator use. These estimates can help inform the development and implementation of strategies to address this gap, including reducing non-COVID-19 demand for services and temporarily increasing system capacity.

According to the WHO report on guidelines to protect COVID-19, [16], it infects humans by enters to the body via different parts such as eyes, nose and/or mouth. It shall be noted that in order to avoid this infection, the guideline by WHO suggests not to touch the face with unwashed hands. Proper washing of hands with detergents such as soap and water for at least 20 seconds, or cleaning hands thoroughly with alcohol-based solutions is recommended in all settings. It is also recommended to stay one meter or more away from one another to reduce the risk of infection through respiratory droplets. COVID-19 spreads rapidly in droplets and somehow surfaces.

Lutfi and Burcu [17] performed Auto Regressive Integrated Moving Average (ARIMA) model on the European Centre for Disease Prevention and Control COVID-19 data to predict the number of cases and deaths in COVID-19. But using some selected countries only. Hiteshi et al. [18] developed a model and then employed it for forecasting future COVID-19 cases in India only. The study indicates an ascending trend for the cases in the coming days.

Previous researchers were focused on developing methods to achieve accurate and time-efficient for prediction of the spread of COVID-19. The main drawbacks of the previous research works were, they use a predictive model that gives less accurate results in some cases. In reference to the above related work on COVID-19, there were great ideas to improve indicates an ascending trend for the cases in the coming days. Previous works lack some promising features that could enable us to predict the highest possible accuracy of the COVID-19 infections of confirmed case will slowdown.

\section{Dataset Description}

To validate our work, we have used the records of COVID-19 data from WHO and Johns Hopkins university official websites. The data basically shows confirmed cases, daily recovery and death rates. In our work, we have considered COVID-19 datasets for the countries such as the US, Italy, Spain, UK, France, Germany, Russia, and Turkey. Table 1 presents a sample of the top countries having maximum number of confirmed cases as of May 9, 2020 and Figure 1 shows the distribution of confirmed cases. Table 2 describes the current active and closed cases where out of the total infected cases, $98 \%$ of the patients in mild conniption and $2 \%$ are in a serious or critical condition. In the cases of closed cases, $84 \%$ of the patients have recovered and $16 \%$ of them have died.

\subsection{Current Statistics}

Age factor and Death Rate due to COVID-19: Table 3 presents the collected data from New York City (NYC) Health as of April 14. All data in this report are preliminary and are subject to change as cases continue to be investigated (See Table 1). These data include cases in NYC residents and foreign residents treated in NYC facilities. This Table shows only confirmed deaths. A death is considered confirmed when the person died after positive COVID-19 laboratory test. The main underlying illnesses that leads to high risk of death 
Table 1: A sample of the top countries sorted by the number of confirmed cases as of May 9, 2020 [8].

\begin{tabular}{|c|c|c|c|c|c|c|c|c|c|c|c|}
\hline $\begin{array}{l}\text { Country, } \\
\text { Other }\end{array}$ & $\begin{array}{l}\text { Total } \\
\text { Cases }\end{array}$ & $\begin{array}{l}\text { New } \\
\text { Cases }\end{array}$ & $\begin{array}{l}\text { Total } \\
\text { Deaths }\end{array}$ & $\begin{array}{l}\text { New } \\
\text { Deaths }\end{array}$ & $\begin{array}{l}\text { Total } \\
\text { Recovered }\end{array}$ & $\begin{array}{l}\text { Active } \\
\text { Cases }\end{array}$ & $\begin{array}{l}\text { Serious, } \\
\text { Critical }\end{array}$ & $\begin{array}{l}\text { Tot Cases/ } \\
1 \mathrm{M} \text { pop }\end{array}$ & $\begin{array}{l}\text { Deaths/ } \\
\text { 1M pop }\end{array}$ & $\begin{array}{l}\text { Total } \\
\text { Tests }\end{array}$ & $\begin{array}{l}\text { Tests/ } \\
\text { 1M pop }\end{array}$ \\
\hline World & $4,065,824$ & $+56,533$ & 278,375 & $+2,399$ & $1,415,268$ & $2,372,181$ & 47,812 & 522 & 35.7 & & \\
\hline USA & $1,332,396$ & $+10,611$ & 79,180 & +565 & 224,633 & $1,028,583$ & 16,843 & 4,025 & 239 & $8,453,409$ & 25,539 \\
\hline Spain & 262,783 & $+2,666$ & 26,478 & +179 & 173,157 & 63,148 & 1,741 & 5,620 & 566 & $2,467,761$ & 52,781 \\
\hline Italy & 218,268 & $+1,083$ & 30,395 & +194 & 103,031 & 84,842 & 1,034 & 3,610 & 503 & $2,514,234$ & 41,584 \\
\hline UK & 215,260 & $+3,896$ & 31,587 & +346 & $\mathrm{~N} / \mathrm{A}$ & 183,329 & 1,559 & 3,171 & 465 & $1,728,443$ & 25,461 \\
\hline Russia & 198,676 & $+10,817$ & 1,827 & +104 & 31,916 & 164,933 & 2,300 & 1,361 & 13 & $5,221,964$ & 35,783 \\
\hline France & 176,079 & & 26,230 & & 55,782 & 94,067 & 2,868 & 2,698 & 402 & $1,384,633$ & 21,213 \\
\hline Germany & 170,998 & +410 & 7,510 & & 143,300 & 20,188 & 1,712 & 2,041 & 90 & $2,755,770$ & 32,891 \\
\hline Brazil & 148,670 & $+2,778$ & 10,100 & +108 & 59,297 & 79,273 & 8,318 & 699 & 48 & 339,552 & 1,597 \\
\hline Turkey & 137,115 & $+1,546$ & 3,739 & +50 & 89,480 & 43,896 & 1,168 & 1,626 & 44 & $1,334,411$ & 15,822 \\
\hline
\end{tabular}

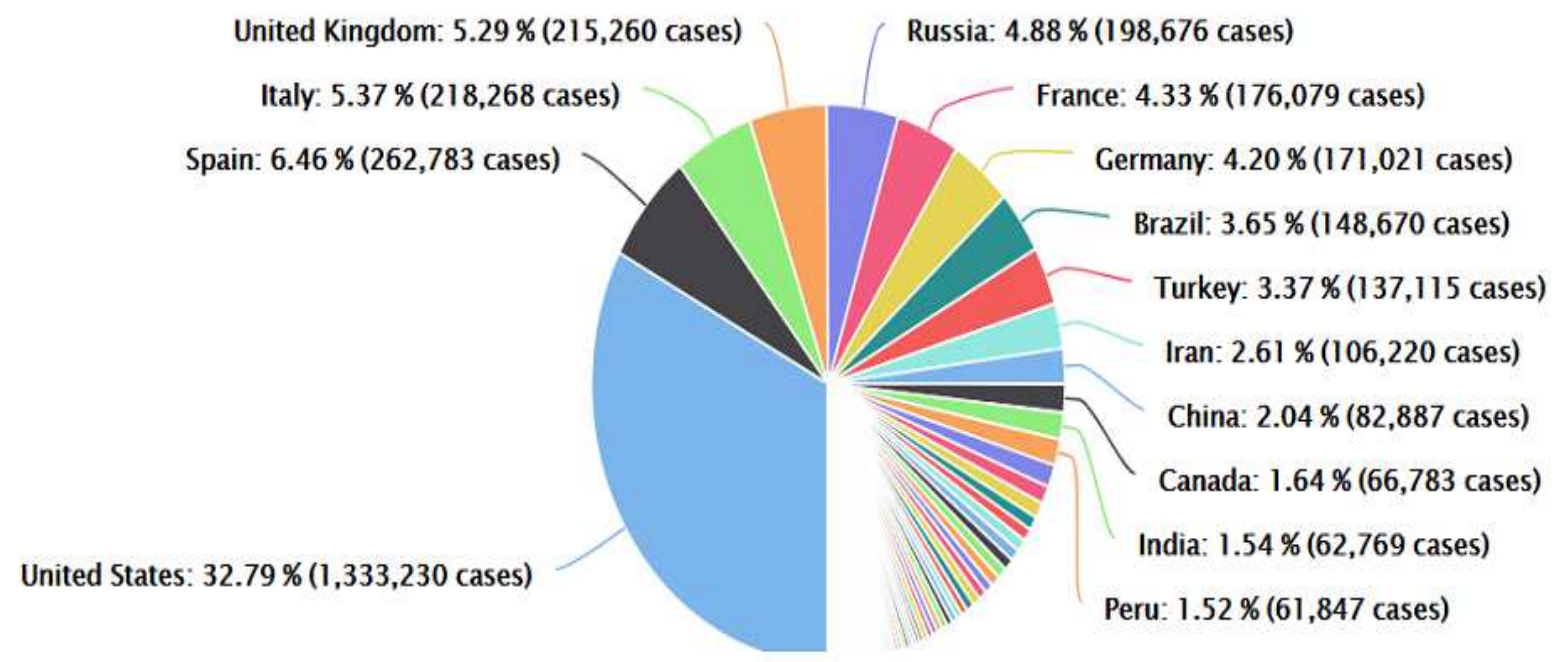

Figure 1: Distribution of cases as of May 9, 2020 [8].

if one has got infected by COVID-19 include diabetes, lung disease, cancer, immunodeficiency, heart disease, hypertension, asthma, kidney disease, and GI/liver disease.

Table 3 depicts the rate of death due to COVID-19 for various age range in the New York City. For people in the age range from 0 to 17 years old, the rate of death is insignificant if the patients do not have underlying health condition. In the case of elderly people whose age is $75+$ years old the rate of death rate $14.2 \%$. Generally, as the age increases and if the patient has underlying health condition, there is high risk of death due to the COVID-19.

Moreover, the data depicts men are highly susceptible to death comparing to that of women. Out of the total death rates, $61.8 \%$ men and $38.2 \%$ women dies due to COVID-19 in the New York city as of April 14 as shown in Table 4.

Table 5 shows the COVID-19 Fatality Rate by AGE in China. The death rate is computed as shown in Equation 1. This probability varies depending on the age group. The percentages shown below do not have to add up to $100 \%$, as they do NOT represent share of deaths by age group. It presents, for a person in a given age group, the risk of dying if infected with COVID-19. In general, relatively few cases are seen among children [19].

Death Rate $=$ (number of deaths/number of cases $)$

Death Rate $=$ probability of dying if infected by the virus $(\%)$.

Table 6 shows COVID-19 Fatality Rate by SEX. The probability differs depending on gender(sex) of the pa- 
Table 2: A sample of the top countries sorted by the number of confirmed cases in May 9, 2020 [8].

\begin{tabular}{|l|l|l|l|}
\hline \multicolumn{2}{|c|}{ ACTIVE CASES } & \multicolumn{2}{c|}{ CLOSED CASES } \\
\hline Currently Infected Patients & $2,372,181$ & Cases which had an outcome: & $1,693,643$ \\
\hline in Mild Condition & $2,324,369(98 \%)$ & Recovered / Discharged & $1,415,268(84 \%)$ \\
\hline Serious or Critical & $47,812(2 \%)$ & Deaths & $278,375(16 \%)$ \\
\hline
\end{tabular}

Table 3: Age of Coronavirus Deaths of New York City Health [8].

\begin{tabular}{|l|l|l|l|l|l|l|}
\hline AGE & Number of Deaths & $\begin{array}{l}\text { Share of } \\
\text { deaths }\end{array}$ & $\begin{array}{l}\text { With underlying } \\
\text { conditions }\end{array}$ & $\begin{array}{l}\text { Without } \\
\text { underlying } \\
\text { conditions }\end{array}$ & $\begin{array}{l}\text { Unknown if with } \\
\text { underlying cond. }\end{array}$ & $\begin{array}{l}\text { Share of deaths } \\
\text { of unknown + w/o cond. }\end{array}$ \\
\hline $\mathbf{0}-\mathbf{1 7}$ & 3 & $\mathbf{0 . 0 4 \%}$ & 3 & 0 & 0 & $0 \%$ \\
\hline $\mathbf{1 8}-\mathbf{4 4}$ & 309 & $\mathbf{4 . 5 \%}$ & 244 & 25 & 40 & $1.0 \%$ \\
\hline $\mathbf{4 5}-\mathbf{6 4}$ & 1,581 & $\mathbf{2 3 . 1 \%}$ & 1,343 & 59 & 179 & $3.5 \%$ \\
\hline $\mathbf{6 5}-\mathbf{7 4}$ & 1,683 & $\mathbf{2 4 . 6 \%}$ & 1,272 & 26 & 385 & $6.0 \%$ \\
\hline $\mathbf{7 5 +}$ & 3,263 & $\mathbf{4 7 . 7 \%}$ & 2,289 & 27 & 947 & $14.2 \%$ \\
\hline TOTAL & $\mathbf{6 , 8 3 9}$ & $100 \%$ & 5,151 & 137 & 1,551 & $24.68 \%$ \\
\hline
\end{tabular}

tients. When reading these numbers, it must be taken into account that smoking in China is much more prevalent among males. Smoking increases the risks of respiratory complications. Hence, male are highly susceptible to death when compared to female which is evidenced empirically as $4.7 \%$ and $2.8 \%$ respectively.

Pre-existing medical conditions (comorbidities) put patients at higher risk of death from COVID-19 pandemic. Patients who have no pre-existing ("comorbidities") medical conditions are having fatality rate of $0.9 \%$.

Table 6 shows COVID-19 Fatality Rate by COMORBIDITY. This probability differs depending on preexisting condition. The percentage shown below does NOT represent in any way the share of deaths by preexisting condition. Rather, it represents, for a patient with a given pre-existing condition, the risk of dying if infected by COVID-19.

\section{Methodology}

In the subsequent subsections, the proposed Auto Regressive Integrated Moving Average (ARIMA) have been described. The ARIMA is a statistical and econometric model applicable in time-series analysis related problems mainly to understand the data or to predict future points in the series.

\subsection{The ARIMA Models}

A time-series $Y_{t}$ is described as a series of independent variables on the basis of time, where $t$ is a time step [20]. A deterministic time- series is expressed by the function, $Y_{t}=f(t)$. While, the stochastic time series is expressed by $Y_{t}=X(t)$, where $X$ is a random variable. The ARMA model developed by Box [21], has been used for the forecasting process in the stationary time series. Box-Jenkins (ARMA) forecasting model is very popular as it has high prediction efficiency in the stationary time series analysis [22]. An autoregression $\mathrm{AR}(\mathrm{p})$ is a known time series method used to predict the future value by using observations from previous $\mathrm{p}$-time steps as inputs to the regression equation multiplied by the appropriate coefficients $\phi$ of AR. Besides, the sum is extended by adding the mean of the series $\mu$ and white noise $\omega$ that is a random error. The $\operatorname{AR}(\mathrm{p})$ model is given in the form shown in equation 2 .

$$
A R(p): y_{t}=\mu+\sum_{i=1}^{p}\left(\phi_{i} y_{t-i}\right)+\omega_{t}
$$

The polynomial function of the Moving Average MA(q) method is not included for any variable from a time-series. It consists of three parts that includes: first part is the mean of the series $\mu$, the second part is summation of the multiplication of a finite number of MA coefficients, $\theta$, and model residuals $\omega$, and the third part is the white noise $\omega_{t}$. The $\operatorname{MA}(\mathrm{q})$ model is given in equation 3 .

$$
\operatorname{MA}(q): y_{t}=\mu+\sum_{i=1}^{q}\left(\theta_{i} \omega_{t-i}\right)+\omega_{t}
$$

The $\operatorname{ARMA}(p, q)$ model composes of two main polynomials which are AR(p) and MA(q) [23]. Mathematically it is represented as shown in Equation 4.

$$
y_{t}=\mu+\sum_{i=1}^{p}\left(\phi_{i} y_{t-i}\right)+\sum_{j=1}^{q}\left(\theta_{j} \omega_{t-j}\right)+\omega_{t}
$$


Table 4: Sex ratio of New York City Health [8].

\begin{tabular}{|c|c|c|c|c|c|c|c|c|}
\hline SEX & Deaths & Share of Deaths & $\begin{array}{l}\text { With underlying } \\
\text { conditions }\end{array}$ & $\begin{array}{l}\text { Share within } \\
\text { this category }\end{array}$ & $\begin{array}{l}\text { Without underlying } \\
\text { conditions }\end{array}$ & $\begin{array}{l}\text { Share within } \\
\text { this category }\end{array}$ & $\begin{array}{l}\text { Unknown if } \\
\text { with cond. }\end{array}$ & $\begin{array}{l}\text { Share within } \\
\text { this category }\end{array}$ \\
\hline Male & 4,095 & $61,8 \%$ & 3,087 & $62,2 \%$ & 96 & $72.2 \%$ & 912 & $59.5 \%$ \\
\hline Female & 2,530 & $38.2 \%$ & 1.873 & $37.8 \%$ & 37 & $27.8 \%$ & 620 & $40.5 \%$ \\
\hline
\end{tabular}

Table 5: Age of Coronavirus Deaths in China [19].

\begin{tabular}{|l|l|l|}
\hline AGE & $\begin{array}{l}\text { DEATH RATE } \\
\text { confirmed cases }\end{array}$ & $\begin{array}{l}\text { DEATH RATE } \\
\text { all cases }\end{array}$ \\
\hline 80+ years old & $\mathbf{2 1 . 9 \%}$ & $\mathbf{1 4 . 8 \%}$ \\
\hline $\mathbf{7 0 - 7 9}$ years old & & $\mathbf{8 . 0 \%}$ \\
\hline 60-69 years old & & $\mathbf{3 . 6 \%}$ \\
\hline 50-59 years old & & $1.3 \%$ \\
\hline 40-49 years old & & $\mathbf{0 . 4 \%}$ \\
\hline 30-39 years old & & $\mathbf{0 . 2 \%}$ \\
\hline $20-29$ years old & & $\mathbf{0 . 2 \%}$ \\
\hline $10-19$ years old & & $0.2 \%$ \\
\hline 0-9 years old & & no fatalities \\
\hline
\end{tabular}

Table 6: Fatality Rate by SEX in China [8].

\begin{tabular}{|l|l|l|}
\hline SEX & $\begin{array}{l}\text { DEATH RATE } \\
\text { confirmed cases }\end{array}$ & $\begin{array}{l}\text { DEATH RATE } \\
\text { all cases }\end{array}$ \\
\hline Male & $\mathbf{4 . 7 \%}$ & $\mathbf{2 . 8 \%}$ \\
\hline Female & $\mathbf{2 . 8 \%}$ & $\mathbf{1 . 7 \%}$ \\
\hline
\end{tabular}

Table 7: Fatality Rate by COMORBIDITY in China [8].

\begin{tabular}{|l|l|l|}
\hline PRE-EXISTING CONDITION & $\begin{array}{l}\text { DEATH RATE } \\
\text { confirmed cases }\end{array}$ & $\begin{array}{l}\text { DEATH RATE } \\
\text { all cases }\end{array}$ \\
\hline Cardiovascular disease & $13.2 \%$ & $10.5 \%$ \\
\hline Diabetes & $9.2 \%$ & $7.3 \%$ \\
\hline Chronic respiratory disease & $8.0 \%$ & $6.3 \%$ \\
\hline Hypertension & $8.4 \%$ & $6.0 \%$ \\
\hline Cancer & $7.6 \%$ & $5.6 \%$ \\
\hline no pre-existing conditions & & $0.9 \%$ \\
\hline
\end{tabular}

In other words, the process $X_{t}$ should be stationary after differencing a non-seasonal process $d$ times. During the training step of the ARIMA model using the available dataset, the values of $p, d$, and $q$ are continually 
changing until the end and the last values are considered for the forecasting of the future values. The mathematical description of the model is presented as shown in Equation 7.

$$
\phi_{p}(B)(1-B)^{d} X_{t}=\mu+\theta(B) \omega_{t}
$$

\subsection{Seasonal ARIMA Model}

The non-seasonal ARIMA model $(p, d, q)$ is vital in building pure seasonal $\operatorname{SARIMA}(p, d, q) \times(P, D, Q)_{s}$ model, whereby the term $(p, d, q)$ presents the nonseasonal part of the model and $(P, D, Q)_{s}$ describes the seasonal part of the model. The mathematical description of the model are presented as shown in Equation 8.

$$
\phi_{p}(B) \Phi_{P}\left(B^{s}\right) W_{t}=\theta_{q}(B) \Theta_{Q}\left(B^{s}\right) \omega_{t}
$$

The notation of equation 8 is described as follows: $p, d, a n d q$ are represented in the previous Equation 4, $P$ presents the order of seasonal AR model, $D$ indicates the number of seasonal differencing, $Q$ refers to the order of seasonal MA, and $s$ is length of the season (periodicity). Besides, the $\omega_{t}$ and $B$ are the white noise value at period $t$, and the backward shift operator, respectively.

Equation 8 presents the seasonal components of SARIMA which can be expanded mathematically after substitute the value of $W_{t}=\nabla^{d}(B) \nabla_{s}^{D}(B) X_{t}$.

$$
\phi_{p}(B) \Phi_{P}\left(B^{s}\right)(1-B)^{d}\left(1-B^{s}\right)^{D} X_{t}=\theta_{q}(B) \Theta_{Q}\left(B^{s}\right) \omega_{t}
$$

The components of seasonal SARIMA can be written as:

- non-seasonal AR: $\phi_{p}(B)=1-\phi_{1} B-\phi_{2} B^{2}-\phi_{3} B^{3}-$ $\cdots-\phi_{p} B^{p}$

- non-seasonal MA: $\theta_{q}(B)=1-\theta_{1} B-\theta_{2} B^{2}-\theta_{3} B^{3}-$ $\cdots-\theta_{q} B^{q}$

- seasonal AR: $\Phi_{P}\left(B^{s}\right)=1-\Phi_{1} B^{s}-\Phi_{2} B^{2 s}-\Phi_{3} B^{3 s}-$ $\cdots-\Phi_{p} B^{p s}$

- seasonal MA: $\Theta_{Q}\left(B^{s}\right)=1-\Theta_{1} B^{s}-\Theta_{2} B^{2 s}-\Theta_{3} B^{3 s}-$ $\cdots-\Theta_{Q} B^{Q s}$

and

- $B^{s} X_{t}=X_{t-s}$,

- $\nabla_{s} X_{t}=\nabla_{s}(B) X_{t}=\left(1-B^{s}\right) X_{t}$ $=X_{t}-B^{s} X_{t}=X_{t}-X_{t-s}$,

- $\nabla^{d}(B) X_{t}=(1-B)^{d} X_{t}$,

- $\nabla_{s}^{D}(B) X_{t}=\left(1-B^{s}\right)^{D} X_{t}$
Considering the relationship within the data, SARIMA $(p, d, q) \times(P, D, Q)_{s}$ model is successfully applied to different time-series because of the order of SARIMA is relatively small number. The period value of time-series $s$ (seasonality) is based on the dataset. For instance, $s=7,30,365$ for weekly, monthly, and yearly data respectively. The $d$ and $D$ indicate the order of the nonseasonal and seasonal differencing and values of it are not more than 1 and 2 total of seasonal difference, respectively (i.e., $0 \leq d, D \leq 1$ ).

\subsection{Model selection}

There are three steps in ARIMA model creation namely identification, parameter estimation, and diagnostic checking [26]. The identification process of the model deals with determining proper differencing to get stationary time-series, the order of the model desired, and the autocorrelation (ACF) and partial autocorrelation (PACF) functions that are used to recognize the temporal correlation structure of the transformed data. $\mathrm{ACF}$ is a statistical metric of the correlation that is used to check if previous values in time-series analysis has certain relationship with the latest values or not. For all low order lags, PACF represents the value of the correlation coefficient between the variable and its time lag [27].

The two main methods commonly used to select appropriate models are Akaike's Information Criterion (AIC) and the Bayesian Information Criterion of Schwarz (BIC) [28] which are presented in Equations 10 and 11 for AIC and BIC respectively.

In this regard, $n$ refers to the size of the series, and $k$ presents the number of the parameters of the ARIMA method. It is experimentally proved that our model becomes efficient when the value of AIC is smaller. According to [21], an optimal forecasting model is selected based on the best fitting that has the minimum AIC value of the group.

$A I C=-2 \log (L)+2 k=-2 \log (L)+2(p+q+P+Q)$

$B I C=-2 \log (L)+k \ln (n)=-2 \log (L)+(p+q+P+Q) \ln (n)$

\section{Experimental Evaluation}

In the subsequent subsections, the experimental results of the proposed method is presented. The experimental results are presented visually and in tabular form and comparative study with state-of-the art methods also presented and discussed. 


\subsection{Experimental Results}

To carry out the experiments, the following machine learning libraries such as sci-kit learn and Stat are used. The experimentations are executed on the Kaggle environment that provides the required packages and the COVID-2019 data collected from January $22^{\text {th }}, 2020$ to the present time were collected from official websites. To attain the best prediction, the different parameters of the proposed model are adjusted by the grid search. The values of parameters have been selected based on the collected data from the corresponding country. For each country, the best parameters of the SARIMA model are identified using a grid search technique, and then $31 \mathrm{fu}-$ ture days are predicted.

To train and validate the proposed SARIMA model, we have used COVID-19 data which is collected official data repository websites of WHO and worldometer $[3,8]$. The proposed method is essentially used to estimate the pandemic life cycle. To select the best parameter of the model, the grid search method is applied on each country's data. The proposed method updates the daily data with the newest version. Table 8 presents an experimental results of the proposed method for the diagnosis test on the Global dataset.

The SARIMA model has the ability of predicting the current time and forecasts the next few weeks. It can estimate the full pandemic life cycle and visualize the corresponding curves. The model is fitted with the training data set followed by validation using test set. The next step, after estimated the full life cycle curve for each country, it determines the peak in the bell-shaped curve to show when the pandemic will stop.

The experimental results of the diagnostic test for SARIMA models that have the lowest values of AIC are presented in Table 8. Moreover, Table 9 shows the experimental results of the diagnostic test for SARIMA models in the US that have p-values $\leq 0.05$, that indicates minimum values of the AIC of each model. For each model, the initial phase creating a set of parameters and initialize them with bench of values. Then, the grid search is applied to find out the optimal model that have minimum values of AIC. The next phase is to select the best combination of parameters that can provide minimum error (AIC) and assigned to the best model.

In our work, we have applied data normalization using the min-max scalar function. Scaling data is a vital task to stabilize the value of variance. Generally, data normalization enhances performance and minimize computational complexity. In this work, Equation 12 is used to normalize all datasets before starting to train the model where $X_{i}$ presents the scaled datasets, $x_{i}$ refers to the actual data, and the terms $\min \left(x_{i}\right)$ and $\max \left(x_{i}\right)$ presents the minimum and maximum values of the actual dataset respectively.

$$
X_{i}=\frac{x_{i}-\min \left(x_{i}\right)}{\max \left(x_{i}\right)-\min \left(x_{i}\right)}
$$

In our work, it is experimentally proved that the model parameters vary from country to country as the data for each country substantially differs. The grid search is a hyperparameter optimization method used to find out the proper combination of parameter values among different combinations and enables to select an optimal model. Since the daily data over few months have used, the value of $s$ is assigned 3,7,12. We selected the best forecasting SARIMA model based on the minimum values of AIC, and P-values that are less than 0.05 . Table 8 presents the AIC values of different forecasting models. The following SARIMA $(1,0,2) \times(1,0,0,3)$ model has the lowest AIC values as shown in Table 9. The best combination of parameters $(1,0,2) \times(1,0,0,3)$ is considered in this work as the best parameters for the corresponding model.

Table 10 presents the final SARIMA models that depicts the lowest AIC values that indicates best parameters used for SARIMA is $(6,0,0) \times(0,0,0,3)$ for Italy. Besides, Table 11 shows experimental results of the diagnostics test for SARIMA models that have $\mathrm{p}$ values less than 0.05. Moreover, the best parameters for SARIMA is based on P-value is $(1,0,2) \times(1,0,0,3)$.

We have split the COVID-19 data into training and testing dataset. The training set comprises from 202001-22 to 2020-04-01 and the testing set is from 202004-01 to current day. Table 12 presents the forecasting values with lower and upper confidence limits that are made using the proposed model for the period from 2020-04-01 to current day. Figure 2 shows the training set typically presented by the green line from 22020-0122 to 2020-04-01 and a comparison between the testing set represented by the green line from 2020-04-01 to present-day and values for one step ahead forecast presented by the red line. In Figure 3, the forecasted values typically presented by the red line and the actual values represented by the blue line and grey shading are used for the confidence intervals with lower and upper confidence limits.

The proposed model predicts the number of the confirmed cases of the next few days or months using the previously observed data as shown in Table 13 with lower and upper confidence limits. Although the increasing trend is visible, the suggested model has better performance for the testing set. Generally, the forecast 
Table 8: Experimental results of the diagnostics test for SARIMA models on the Global COVID-19 data.

\begin{tabular}{|l|l|l|l|l|l|l|l|l|l|}
\hline$(\mathbf{p , d}, \mathbf{q})$ & $\mathbf{( P , D , Q , s )}$ & AIC & MAPE & MAE & MPE & MSE & RMSE & Corr & MinMax \\
\hline$(1,0,2)$ & $(1,0,0,3)$ & -837.021 & 16.7682 & 1.58482 & 11.1522 & 2.51361 & 1.58544 & 0.999584 & 0.920904 \\
\hline$(6,0,0)$ & $(0,0,0,3)$ & -833.547 & 16.249 & 1.46285 & 10.7065 & 2.14488 & 1.46454 & 0.998231 & 0.905508 \\
\hline$(6,0,0)$ & $(0,0,0,7)$ & -833.547 & 16.249 & 1.46285 & 10.7065 & 2.14488 & 1.46454 & 0.998231 & 0.905508 \\
\hline$(6,0,0)$ & $(0,0,0,12)$ & -833.547 & 16.249 & 1.46285 & 10.7065 & 2.14488 & 1.46454 & 0.998231 & 0.905508 \\
\hline
\end{tabular}

Table 9: Experimental results of the diagnostics test for SARIMA models that have p-values less than 0.05 for Global.

\begin{tabular}{|l|l|l|l|l|l|l|l|l|l|}
\hline$(\mathbf{p , d}, \mathbf{q})$ & $\mathbf{( P , D , Q , s )}$ & AIC & MAPE & MAE & MPE & MSE & RMSE & Corr & MinMax \\
\hline$(1,0,2)$ & $(1,0,0,3)$ & -837.021 & 16.7682 & 1.58482 & 11.1522 & 2.51361 & 1.58544 & 0.999584 & 0.920904 \\
\hline$(1,0,2)$ & $(0,1,0,3)$ & -821.434 & 16.7404 & 1.57724 & 11.1269 & 2.48903 & 1.57767 & 0.999695 & 0.919988 \\
\hline$(1,0,2)$ & $(1,1,0,3)$ & -803.28 & 17.1294 & 1.66065 & 11.4598 & 2.76986 & 1.66429 & 0.998445 & 0.928706 \\
\hline$(1,0,1)$ & $(1,0,0,3)$ & -784.425 & 16.792 & 1.60757 & 11.1897 & 2.58974 & 1.60927 & 0.998807 & 0.924092 \\
\hline$(1,0,2)$ & $(1,0,1,3)$ & -780.793 & 15.3129 & 1.31378 & 9.93812 & 1.75551 & 1.32496 & 0.993961 & 0.884553 \\
\hline
\end{tabular}

performance is acceptable when the MSE, RMSE values for the testing set from 2020-04-01 to present-day are 2.51361 , and 1.58544 , respectively.

\subsection{The Risk of Second Rebound of COVID-19 Pan- demic}

Epidemiologically, the history of the deadly pandemic viral infections demonstrates that after getting to the end, they are usually followed by waves of significant spread and deaths. For example, the Spanish flu first appeared in the US and then transmitted to Europe via World War I soldiers in early March 1918. It had all the hallmarks of the seasonal flu, albeit a highly contagious and infectious strains. Yet the first wave of the virus did not appear to be particularly deadly, with symptoms like high fever and malaise usually lasting only three days. There was hope at the beginning of August that the virus had run its course. Somewhere in Europe, a mutated strain of the Spanish flu virus had emerged. This mutated virus that spread by the end of wartime troop movements -from England to France, Africa and the US- caused the fatal severity of the Spanish flu's "second rebound". Another example was the H7N9 pandemic. Since its emergence in March 2013, novel avian influenza A H7N9 virus has triggered five epidemics of human infections in China. This raises concerns about the pandemic threat of this quickly evolving H7N9 subtype for humans [29, 30, 31, 32].

The worrying thing is that many countries are preparing to ease their lockdowns while planning to continuously monitor potential new cases to prevent a second deadly outbreak. The uneven progress of countries' efforts to control the virus has led health researchers to warn that nations will have to monitor closely for new infections and adjust the measures in place until a vaccine is available [3,4]. China's aggressive controls over the daily life have nearly brought the first wave of COVID-19 to an end, however, the danger of a second wave remains high.

While these control measures appear to have reduced the number of infections to very low levels, without herd immunity against COVID-19, cases could easily resurge as businesses, factory operations and schools gradually resume and increase social mixing, particularly given the increasing risk of imported cases from overseas as COVID-19 continues to spread globally. World leaders and health officials are warning that hard-won gains must not be jeopardized by people relaxing physical distancing measures [33, 34].

From the outset of this worldwide pandemic multiple models have been generated by different organizations from around the globe. Generally, models present worse- and best-case scenarios, under different sets of circumstances. With each model, the timing, height, and width of the peak of confirmed coronavirus cases as well as Covid-19 deaths are uncertain. This is due mainly to stochasticity or randomness in the dynamics of virus transmission, as well as uncertainty in key epidemiological parameters.

Furthermore, in Figure 4, the green line represents the healthcare system capacity. Besides lowering the morbidity and mortality indices, the aim of social distancing measures is to ensure there isn't overburdening of the healthcare system.

With acknowledging the uncertain nature of the ongoing COVID-19 pandemic and our growing interconnected and complex world, what is eventually and fundamentally needed are the flexibility, robustness and 
Table 10: Experimental results of the diagnostics test for SARIMA models that have the lowest AIC values for Italy.

\begin{tabular}{|l|l|l|l|l|l|l|l|l|l|}
\hline$(\mathbf{p , d}, \mathbf{q})$ & $(\mathbf{P , D , Q , s})$ & AIC & MAPE & MAE & MPE & MSE & RMSE & Corr & MinMax \\
\hline$(6,0,0)$ & $(0,0,0,3)$ & -655.818 & 1.66413 & 0.53509 & 1.66413 & 0.34442 & 0.586873 & 0.737559 & 0.477072 \\
\hline$(6,0,0)$ & $(0,0,0,7)$ & -655.818 & 1.66413 & 0.53509 & 1.66413 & 0.34442 & 0.586873 & 0.737559 & 0.477072 \\
\hline$(6,0,0)$ & $(0,0,0,12)$ & -655.818 & 1.66413 & 0.53509 & 1.66413 & 0.34442 & 0.586873 & 0.737559 & 0.477072 \\
\hline$(6,0,1)$ & $(0,0,0,3)$ & -653.229 & 1.66143 & 0.533291 & 1.66143 & 0.343017 & 0.585677 & 0.724816 & 0.476041 \\
\hline
\end{tabular}

Table 11: Experimental results of the diagnostics test for SARIMA models that have p-values less than 0.05 for Italy.

\begin{tabular}{|l|l|l|l|l|l|l|l|l|l|}
\hline$(\mathbf{p , d}, \mathbf{q})$ & $(\mathbf{P , D}, \mathbf{Q})$ & AIC & MAPE & MAE & MPE & MSE & RMSE & Corr & MinMax \\
\hline$(1,0,2)$ & $(1,0,0,3)$ & -644.731 & 1.67929 & 0.552437 & 1.67929 & 0.351672 & 0.593019 & 0.972171 & 0.489233 \\
\hline$(1,0,2)$ & $(0,1,0,3)$ & -627.002 & 1.75786 & 0.612724 & 1.75786 & 0.403636 & 0.635324 & 0.999682 & 0.520577 \\
\hline$(1,0,2)$ & $(1,1,0,3)$ & -624.865 & 1.84025 & 0.674041 & 1.84025 & 0.469313 & 0.685064 & 0.997189 & 0.547567 \\
\hline$(1,0,0)$ & $(1,0,2,3)$ & -603.812 & 1.80546 & 0.643323 & 1.80546 & 0.436218 & 0.660468 & 0.999215 & 0.534076 \\
\hline$(1,0,1)$ & $(1,1,0,3)$ & -602.847 & 1.91468 & 0.722273 & 1.91468 & 0.530755 & 0.72853 & 0.995715 & 0.565759 \\
\hline
\end{tabular}

Table 12: Experimental results for the proposed SARIMA $(1,0,2) \times(1,0,0,3)$ model (from $1^{\text {st }}$ of April until $30^{\text {th }}$ of April) with $95 \%$ CI.

\begin{tabular}{|c|c|c|c|c|c|c|c|c|c|}
\hline Date & ctual & redicted & Lower & Upper & Date & Actual & Predicted & Lower & Upper \\
\hline 2020-04-01 & 6839.0 & $166901 \mathrm{e}+05$ & $9.041690 \mathrm{e}+05$ & $9.292111 \mathrm{e}+05$ & 2020-04-16 & 2110565.0 & $2.094475 e+06$ & $2.081969 \mathrm{e}+06$ & $2.106981 e+06$ \\
\hline 2020-04-02 & & $897019 e+05$ & $771835 e+05$ & $.002220 \mathrm{e}+06$ & $20-04-17$ & 196276.0 & $2.202708 \mathrm{e}+06$ & $2.190203 \mathrm{e}+06$ & $2.215212 \mathrm{e}+06$ \\
\hline 2020-04-03 & & & $22 \mathrm{e}+06$ & $58 e+06$ & & & $e+06$ & $61 \mathrm{e}+06$ & $70 e+06$ \\
\hline 2020-04-04 & 25.0 & $48 \mathrm{e}+06$ & $531 e+06$ & $65 e+06$ & 0-04-19 & 70.0 & $37 e+06$ & $433 e+06$ & $2.360441 \mathrm{e}+06$ \\
\hline 2020-04-05 & 226195.0 & $.234152 e+06$ & $1.221637 \mathrm{e}+06$ & $1.246667 \mathrm{e}+06$ & $0-04-20$ & & $31 \mathrm{e}+06$ & $2.422528 \mathrm{e}+06$ & $2.447534 \mathrm{e}+06$ \\
\hline 2020-04-06 & 296809.0 & $1.298666 \mathrm{e}+06$ & $1.286152 \mathrm{e}+06$ & $1.311181 \mathrm{e}+06$ & 2020-04-21 & 2498424.0 & $2.494278 \mathrm{e}+06$ & $2.481775 e+06$ & $2.506780 \mathrm{e}+06$ \\
\hline 2020-04-07 & & +06 & $1 \mathrm{e}+06$ & $8 e+06$ & & & $1 e+06$ & $418 \mathrm{e}+06$ & $423 e+06$ \\
\hline 2020-04-08 & 79.0 & $e+06$ & $97 \mathrm{e}+06$ & $1 e+06$ & $\overline{04-23}$ & 7.0 & $1 \mathrm{e}+06$ & $50 \mathrm{e}+06$ & $352 e+06$ \\
\hline 2020-04-09 & & $3 e+06$ & $36 \mathrm{e}+06$ & $9 e+06$ & $\overline{04-24}$ & & $3 e+06$ & $37 e+06$ & $639 e+06$ \\
\hline 2020-04-10 & 39.0 & $e+06$ & $1.606912 \mathrm{e}+06$ & $934 \mathrm{e}+06$ & $0-04-25$ & 682.0 & $7 e+06$ & $2.811877 \mathrm{e}+06$ & $2.836878 \mathrm{e}+06$ \\
\hline 2020-04-11 & & $2+06$ & $2 e+06$ & $0 \mathrm{e}+06$ & $0-04-26$ & 49.0 & $4 \mathrm{e}+06$ & $354 \mathrm{e}+06$ & $7354 \mathrm{e}+06$ \\
\hline 2020-04-12 & 17.0 & $e+06$ & $59 \mathrm{e}+06$ & $7 e+06$ & $0-04-27$ & & $8 e+06$ & $228 \mathrm{e}+06$ & $228 \mathrm{e}+06$ \\
\hline 2020-04-13 & 27.0 & $e+06$ & $727 e+06$ & $1743 e+06$ & $0-04-28$ & 0.0 & $37 e+06$ & $3.016238 \mathrm{e}+06$ & $3.041237 \mathrm{e}+06$ \\
\hline $2020-04-14$ & & $e+06$ & $49 e+06$ & $2 \mathrm{e}+06$ & 04-29 & 2.0 & $40 \mathrm{e}+06$ & $3.091042 \mathrm{e}+06$ & $3.116039 \mathrm{e}+06$ \\
\hline 2020-04-15 & 2017202.0 & $2.010303 e+06$ & $1.997797 \mathrm{e}+06$ & $2.022810 \mathrm{e}+06$ & $2020-04-30$ & 3189602.0 & $3.182357 \mathrm{e}+06$ & $3.169858 \mathrm{e}+06$ & $3.194855 e+06$ \\
\hline
\end{tabular}

Table 13: The forecasted values of daily confirmed cases for 30 days using SARIMA $(1,0,2) \times(1,0,0,3)$ model with $95 \%$ CI.

\begin{tabular}{|c|c|c|c|c|c|c|c|}
\hline Date & Predicted & Lower & Upper & Date & Predicted & Lower & Upper \\
\hline 2020-05-01 & $3.272533 e+06$ & $3.260034 \mathrm{e}+06$ & $3.285031 \mathrm{e}+06$ & $2020-05-16$ & $4.485188 \mathrm{e}+06$ & $4.205193 e+06$ & $4.765182 \mathrm{e}+06$ \\
\hline 2020-05-02 & $3.357697 \mathrm{e}+06$ & $3.345199 \mathrm{e}+06$ & $3.370194 \mathrm{e}+06$ & 2020-05-17 & $4.567652 \mathrm{e}+06$ & $4.249957 \mathrm{e}+06$ & $4.885346 \mathrm{e}+06$ \\
\hline 2020-05-03 & $3.440749 \mathrm{e}+06$ & $3.428252 \mathrm{e}+06$ & $3.453247 \mathrm{e}+06$ & 2020-05-18 & $4.652433 e+06$ & $4.295273 e+06$ & $5.009592 \mathrm{e}+06$ \\
\hline 2020-05-04 & $3.510172 \mathrm{e}+06$ & $3.497675 \mathrm{e}+06$ & $3.522669 \mathrm{e}+06$ & 2020-05-19 & $4.737429 \mathrm{e}+06$ & $4.339237 \mathrm{e}+06$ & $5.135621 \mathrm{e}+06$ \\
\hline 2020-05-05 & $3.580925 e+06$ & $3.568428 \mathrm{e}+06$ & $3.593422 \mathrm{e}+06$ & $2020-05-20$ & $4.820992 \mathrm{e}+06$ & $4.380319 \mathrm{e}+06$ & $5.261666 \mathrm{e}+06$ \\
\hline $2020-05-06$ & $3.666775 e+06$ & $3.654278 \mathrm{e}+06$ & $3.679272 \mathrm{e}+06$ & $2020-05-21$ & $4.906868 \mathrm{e}+06$ & $4.422095 \mathrm{e}+06$ & $5.391641 \mathrm{e}+06$ \\
\hline 2020-05-07 & $3.747580 \mathrm{e}+06$ & $3.719854 \mathrm{e}+06$ & $3.775306 \mathrm{e}+06$ & 2020-05-22 & $4.992967 e+06$ & $4.462643 e+06$ & $5.523291 \mathrm{e}+06$ \\
\hline $2020-05-08$ & $3.826878 \mathrm{e}+06$ & $3.780751 \mathrm{e}+06$ & $3.873004 \mathrm{e}+06$ & $2020-05-23$ & $5.077653 e+06$ & $4.500427 \mathrm{e}+06$ & $5.654878 \mathrm{e}+06$ \\
\hline 2020-05-09 & $3.908508 \mathrm{e}+06$ & $3.840846 \mathrm{e}+06$ & $3.976170 \mathrm{e}+06$ & $2020-05-24$ & $5.164646 \mathrm{e}+06$ & $4.539007 \mathrm{e}+06$ & $5.790284 \mathrm{e}+06$ \\
\hline 2020-05-10 & $3.990329 \mathrm{e}+06$ & $3.898623 \mathrm{e}+06$ & $4.082035 \mathrm{e}+06$ & $2020-05-25$ & $5.251871 \mathrm{e}+06$ & $4.576451 \mathrm{e}+06$ & $5.927290 \mathrm{e}+06$ \\
\hline 2020-05-11 & $4.070660 \mathrm{e}+06$ & $3.952718 \mathrm{e}+06$ & $4.188601 \mathrm{e}+06$ & $2020-05-26$ & $5.337701 \mathrm{e}+06$ & $4.611223 \mathrm{e}+06$ & $6.064179 \mathrm{e}+06$ \\
\hline 2020-05-12 & $4.153319 \mathrm{e}+06$ & $4.006792 \mathrm{e}+06$ & $4.299846 \mathrm{e}+06$ & 2020-05-27 & $5.425834 \mathrm{e}+06$ & $4.646866 \mathrm{e}+06$ & $6.204802 \mathrm{e}+06$ \\
\hline 2020-05-13 & $4.236176 \mathrm{e}+06$ & $4.059061 \mathrm{e}+06$ & $4.413291 \mathrm{e}+06$ & 2020-05-28 & $5.514208 \mathrm{e}+06$ & $4.681447 \mathrm{e}+06$ & $6.346969 \mathrm{e}+06$ \\
\hline 2020-05-14 & $4.317563 e+06$ & $4.108056 \mathrm{e}+06$ & $4.527070 \mathrm{e}+06$ & 2020-05-29 & $5.601207 e+06$ & $4.713430 \mathrm{e}+06$ & $6.488984 \mathrm{e}+06$ \\
\hline $2020-05-15$ & $4.401272 \mathrm{e}+06$ & $4.157389 \mathrm{e}+06$ & $4.645155 e+06$ & $2020-05-30$ & $5.690504 \mathrm{e}+06$ & $4.746342 \mathrm{e}+06$ & $6.634667 \mathrm{e}+06$ \\
\hline
\end{tabular}




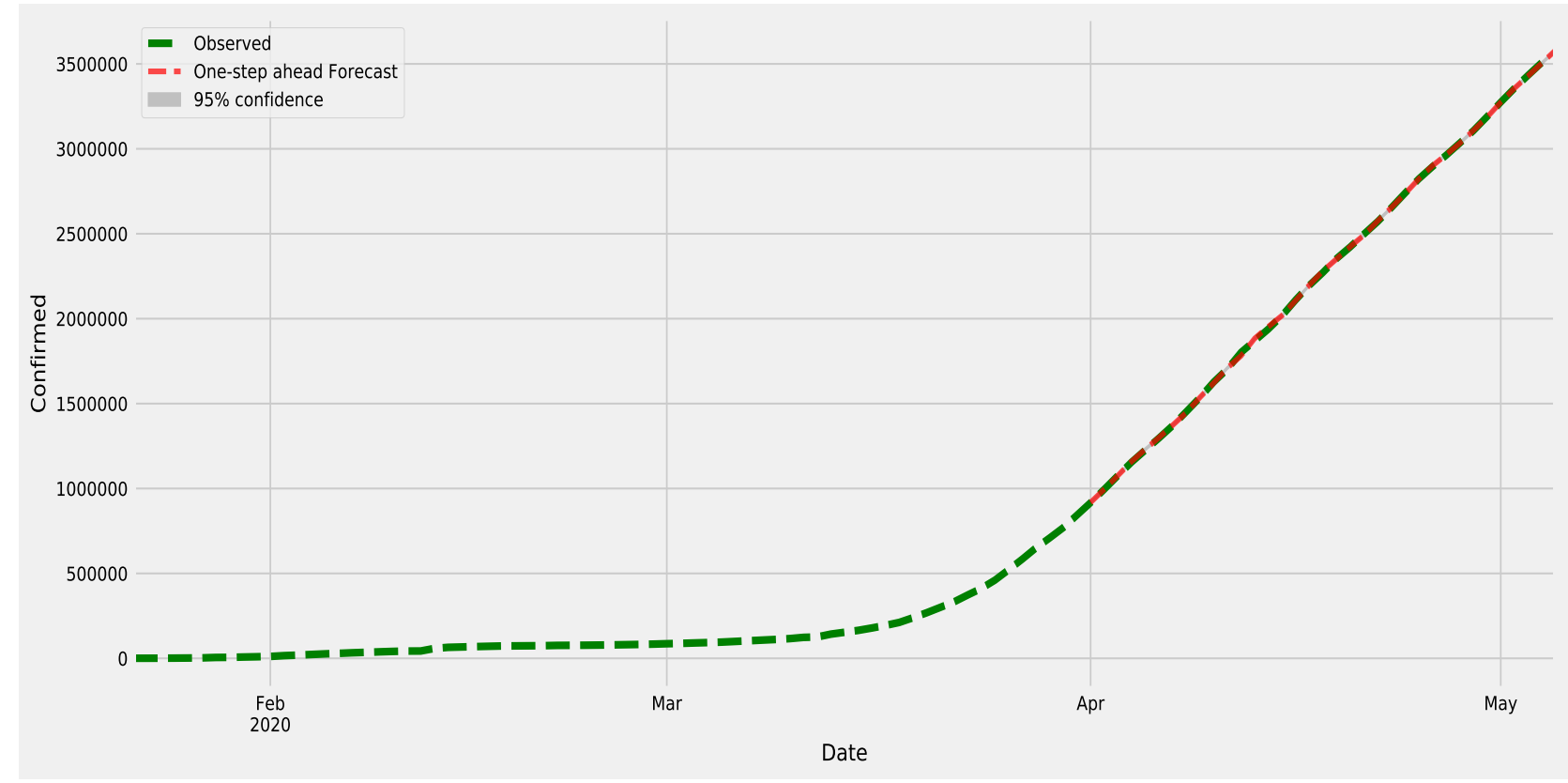

Figure 2: Comparison between the observed and predicted values (one-step ahead result) for SARIMA model on COVID-19 dataset.

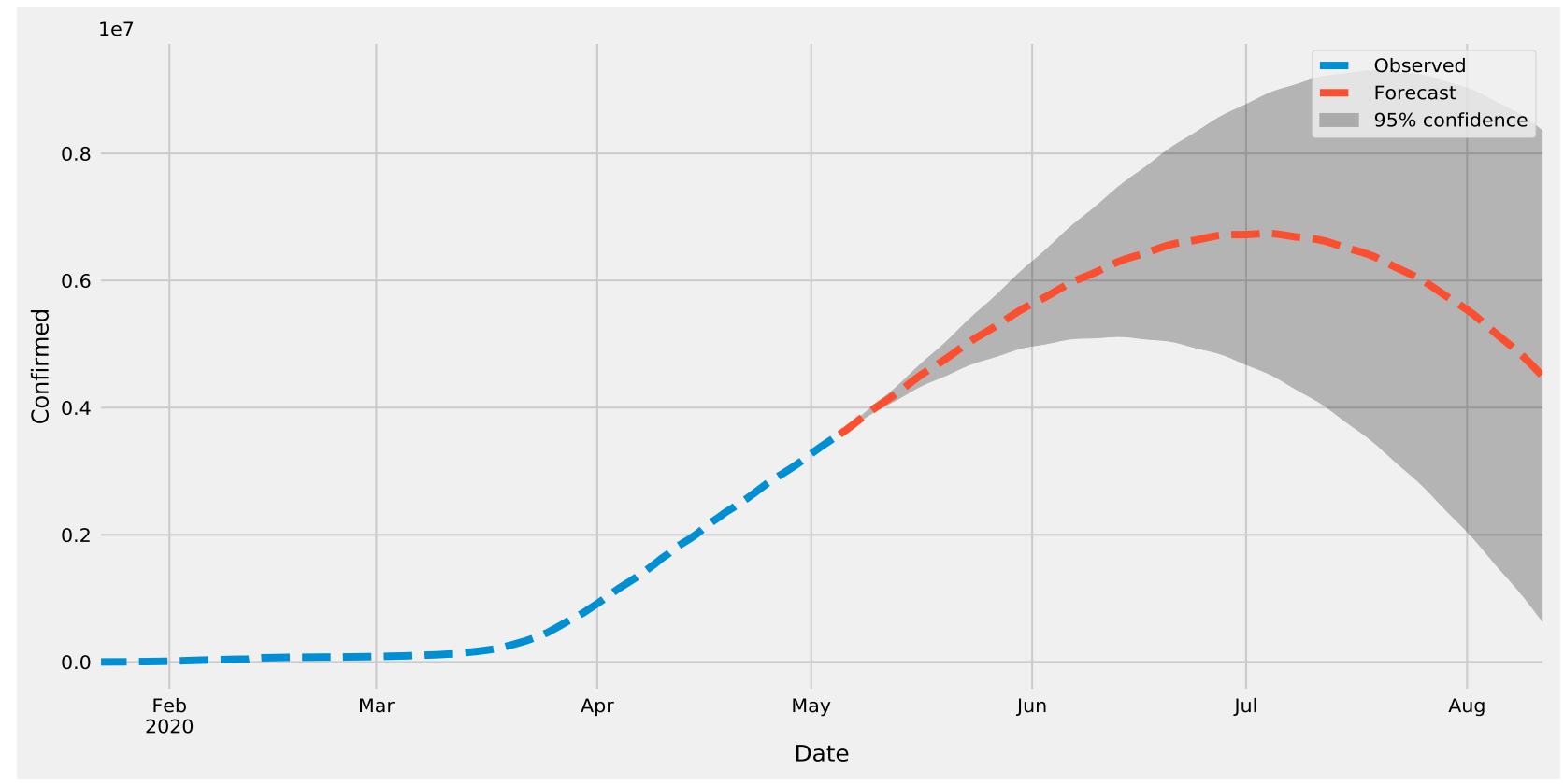

Figure 3: The forecasted values for the COVID-19 new cases over Globe until August 15, 2020. 
resilience to deal with unexpected future events and scenarios.

\subsection{Estimation of slowdown of COVID-19}

The coronavirus is similar to other pandemics in terms of life cycle pattern which includes the outbreak phase, inflection (peak) point, slowdown phase and finally stop. Furthermore, the nature of COVID-19 is not completely random. Based on the different phases of the life cycles of COVID-19 at a specific point in time. Each country has a different starting date of the first phase based on the first confirmed case. For Example, on January 15, in the US, and Italy on January 312020.

The basic idea of our assessment is based on the assumption that the data follows the normal distribution. This study proposes a predictive model that can estimate the expected period of time that the virus can possibly be stopped. The inflection point is specific as it appears like the peak in the bell-shaped curve. The proposed method depicts the possible stoppage of the pandemic using the normal distribution presented in Figure 5 that indicates the area under the curve and the dispersed variability of the daily spread rate of the pandemic. However, estimating the ending date varies based on different considerations such as the first confirmed case and protective measures. Theoretically, one can define the end date as the one with the last predicted case in the pandemic life cycle curve. One might consider an early date as the end date from businesses, schools or governments when most of the predicted infections (indicated by the regressed pandemic life cycle curve) have been actualized and only a small portion of the total predicted epidemic population is left.

It specifically presents the statistical estimation of the slow down period of the pandemic which is extracted based on the concept of normal distribution. The following equations explain how to calculate the area under the curve between $\mu+2 \sigma$ and $\mu+3 \sigma$. Therefore, this approach selected the period of time that the virus can possibly be stopped between $\mu+2 \sigma$ and $\mu+3 \sigma$.

$$
\begin{gathered}
p(\mu+2 \sigma<X<\mu+3 \sigma)=p\left(\frac{\mu+2 \sigma-\mu}{\sigma}<Z<\frac{\mu+3 \sigma-\mu}{\sigma}\right) \\
=p\left(\frac{2 \sigma}{\sigma}<Z<\frac{3 \sigma}{\sigma}\right)=p(2<Z<3)=2.1 \%
\end{gathered}
$$

Figure 6 shows the confidence intervals (C.I) for the expected total cases that have been identified and calculated as follows:

$$
p(\mu-2 \sigma<Z<\mu+2 \sigma)=95.46 \%
$$

$$
p(\mu-3 \sigma<Z<\mu+3 \sigma)=99.73 \%
$$

The final predictions provide the following three estimates of end dates namely: 1) The period estimation from $\mu+2 \sigma$ to $\mu+3 \sigma$ with probability $2.1 \%$ presents the last expected cases have identified as shown in Figure 5. 2) The period estimation from $\mu-2 \sigma$ to $\mu+2 \sigma$ presents $95.46 \%$ of the expected total cases that have been identified. 3) The period estimation from $\mu-3 \sigma$ to $\mu+3 \sigma$ presents the date when $99.73 \%$ of the expected cases have been identified as shown in Figure 6.

In this study, the predictive SARIMA model is used to estimate the expected period of time that the virus can possibly be stopped for the considered countries. Table 14 presents the experimental results of the proposed model that expected deadline for top forecasted countries. Table 14 records the values of the estimation with/without forecasting that has the attributes: country name, the confirmed case $\&$ the first confirmed date, peak point (the top of the bell-shaped curve), the start date is the first expected date with confidence interval $95 \%$, the end date (the last expected date) with confidence interval 99\%, start value (the corresponding value of the start date), and the end value is the corresponding value of the end date.

Moreover, in the case of without forecasting approach, Table 14 shows the prediction of the deadline to end the pandemic for France using the real data and the results showed that expected number of confirmed cases will be 1136.0 on July 3, 2020, and after a month that is on August 2, 2020, the number of confirmed cases will decrease to 6.0. When forecasting approach is applied, the proposed method exhibited different results. The expected number of confirmed cases will be 12758.0 on August 20, 2020, and after a month that is on September 27,2020 , the number of confirmed cases will decrease to 11 as shown in Figure 7.

As presented in Table 14, which presents the forcasting of the end date of the pandemic in Spain, when forecasting approach is applied, the proposed method exhibited different results. The expected number of confirmed cases will be 49515.0 on August 7, 2020, and after a month that is on September 12, 2020, the number of confirmed cases will decrease to 2 as shown in Figure 8

Table 14 shows the forecasted time for the US by applying forecasting approach, the proposed method exhibited different results. The expected number of confirmed cases will be 13747.0 on August 23, 2020 and after a month and a half that is on October 1, 2020, the number of confirmed cases will decrease to 11 as shown in Figure 9. 


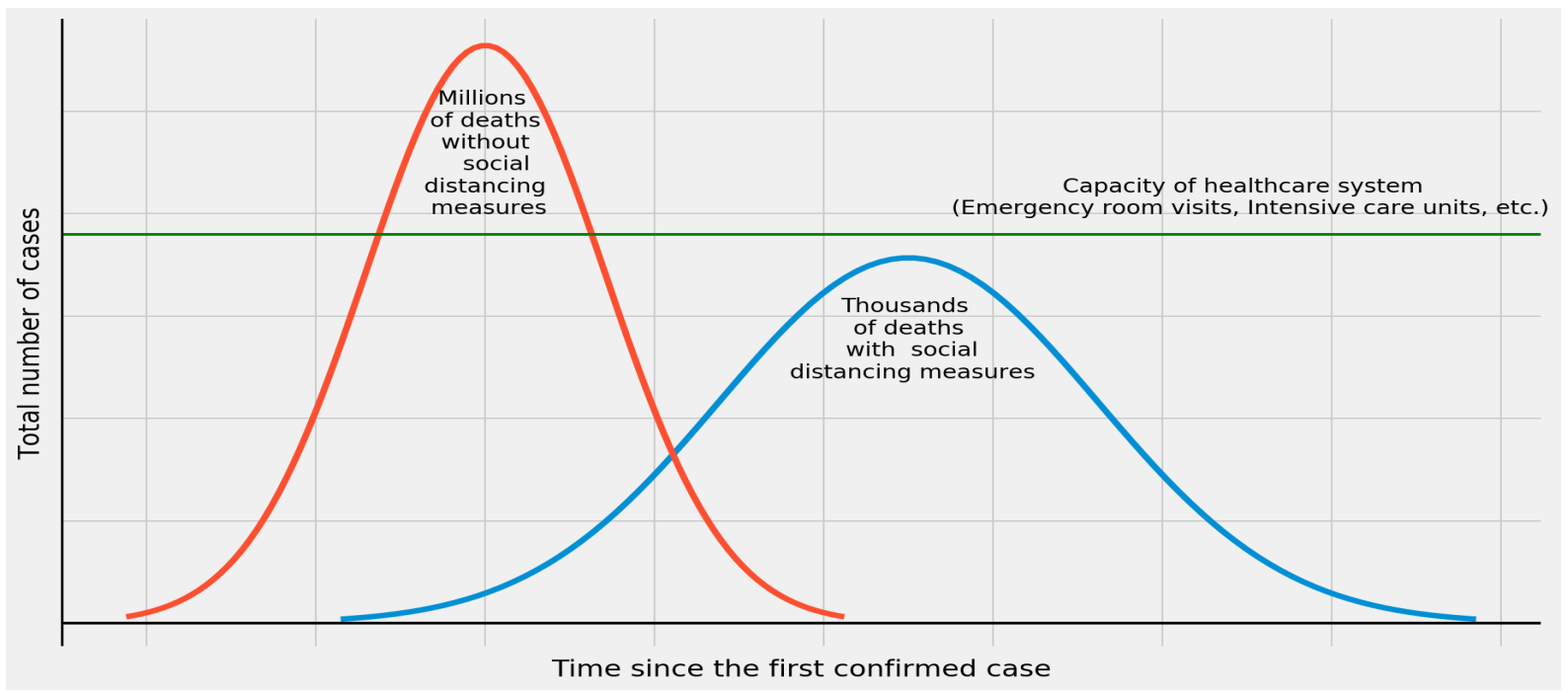

Figure 4: Death flatten curve.

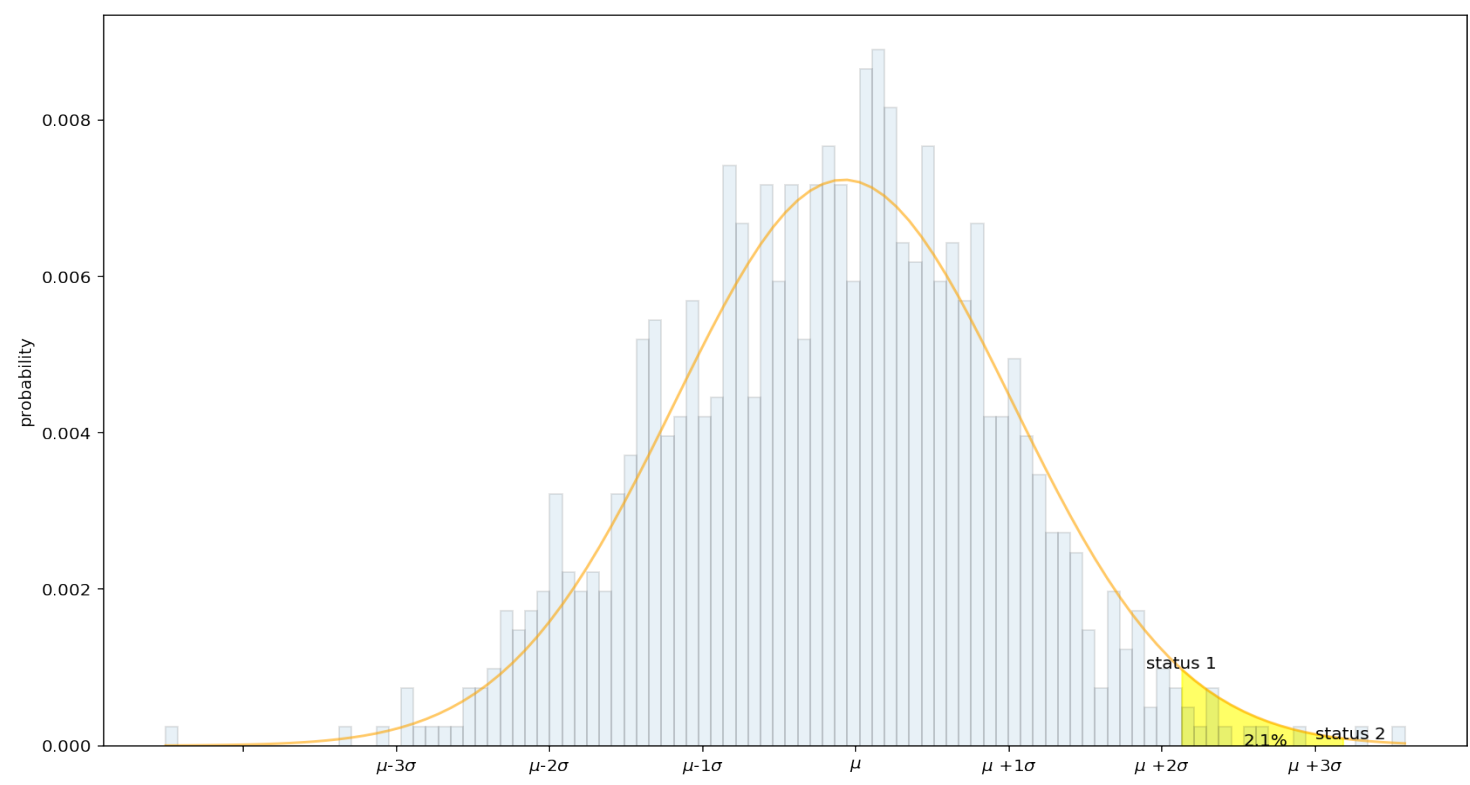

Figure 5: The normal distribution is within 1 standard deviation $(\sigma)$ of the mean $(\mu)$ using SARIMA.

Furthermore as presented in Table 14, for Russia when forecasting approach is applied, the proposed method exhibited various results. The expected number of confirmed cases will be 495.0 on August 9, 2020 and after a month that is on September 14, 2020, the number of confirmed cases will decrease to 2 as shown in Figure 10.

China was successful in haltering COVID-19 epidemic because of the government of China started quarantine early. The confirmed cases trend in China be- comes stable and frequently between zero and one. The study shows Spain and Italy had an unstable trend. This fact indicates that quarantine worked well to reduce human exposure and control the epidemic.

Finally, in general the expected for the top countries of the highest number of the confirmed case will slowdown in October 2020 as shown in Figure 3. Moreover, these predictions may vary based on many factors such as the lockdown period or developing an effective vaccine against COVID-19. 
Table 14: Expected Dead line for Top countries with forecasting COVID-19.

\begin{tabular}{|c|c|c|c|c|c|c|c|c|c|c|c|}
\hline \multirow{2}{*}{ Country } & \multirow{2}{*}{$\begin{array}{c}\text { First } \\
\text { confirmed } \\
\text { case }\end{array}$} & \multicolumn{5}{|c|}{ Estimation without Forecasting } & \multicolumn{5}{|c|}{ Estimation with Forecasting } \\
\hline & & Top point & $\begin{array}{l}\text { Start Date } \\
\mathbf{9 5 \%}\end{array}$ & $\begin{array}{l}\text { End Date } \\
\mathbf{9 9 \%}\end{array}$ & Start Value & End Value & Top point & $\begin{array}{l}\text { Start Date } \\
\mathbf{9 5 \%}\end{array}$ & $\begin{array}{l}\text { End Date } \\
99 \%\end{array}$ & Start Value & End Value \\
\hline US & $2020-01-22$ & $2020-05-06$ & $2020-07-06$ & $2020-08-06$ & 402.0 & 11.0 & $2020-05-30$ & $2020-08-23$ & $2020-10-01$ & 13747.0 & 11.0 \\
\hline Spain & $2020-02-01$ & $2020-05-06$ & $2020-06-21$ & $2020-07-18$ & 2277.0 & 2.0 & $2020-06-09$ & $2020-08-07$ & $2020-09-12$ & 49515.0 & 2.0 \\
\hline Italy & $2020-01-31$ & $2020-05-06$ & $2020-06-22$ & $2020-07-20$ & 12462.0 & 3.0 & $2020-06-08$ & $2020-08-09$ & $2020-09-14$ & 69176.0 & 3.0 \\
\hline France & $2020-01-24$ & $2020-05-06$ & $2020-07-03$ & $2020-08-02$ & 1136.0 & 6.0 & $2020-06-01$ & $2020-08-20$ & $2020-09-27$ & 12758.0 & 11.0 \\
\hline United Kingdom & $2020-01-31$ & $2020-05-06$ & $2020-06-22$ & $2020-07-20$ & 459.0 & 9.0 & $2020-06-08$ & 2020-08-09 & $2020-09-14$ & 8164.0 & 9.0 \\
\hline Germany & $2020-01-27$ & $2020-05-06$ & $2020-06-29$ & $2020-07-28$ & 1176.0 & 14.0 & $2020-06-04$ & $2020-08-15$ & $2020-09-22$ & 24873.0 & 16.0 \\
\hline Russia & $2020-01-31$ & $2020-05-06$ & $2020-06-22$ & $2020-07-20$ & 28.0 & 2.0 & $2020-06-08$ & $2020-08-09$ & $2020-09-14$ & 495.0 & 2.0 \\
\hline
\end{tabular}

\subsection{Comparison with other Models}

Table 15 presents the comparison with the stateof-the-art model for top countries. The estimated of COVID-19 end dates of top countries with forecasting as of October 2020 with $99.73 \%$ percentage. For example, the end date for the-state-of-art methods for the US is August $27^{\text {th }}, 2020$ while our model's prediction date is on October $15^{\text {th }}, 2020$ which is statistically more accurate. In any case, prediction and specifying an end date is arbitrary in nature. Alternatively, estimation as

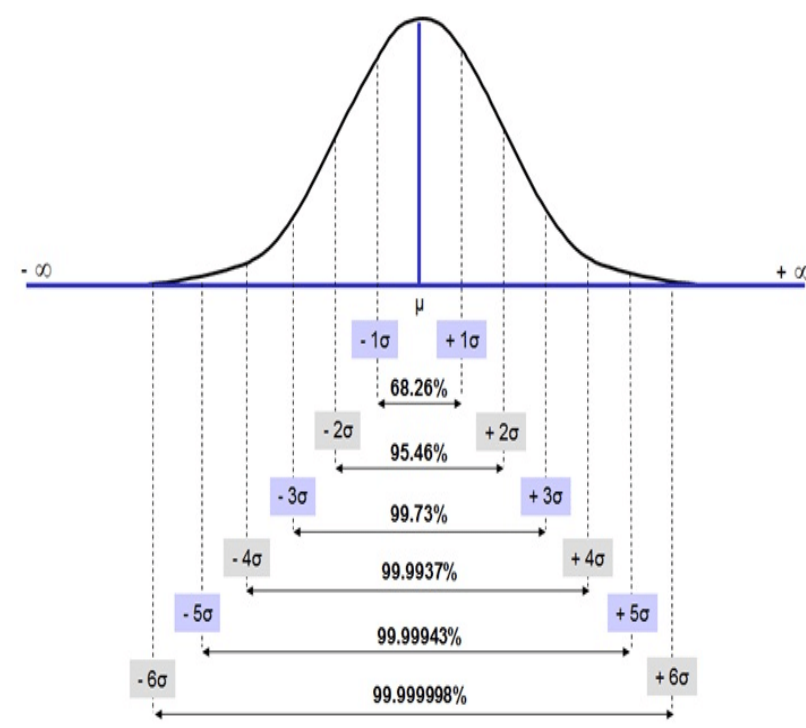
a range of dates might make sense for such uncertain predictions. The estimated date range is expected to become narrower as the countries continually evolve along the pandemic life cycle curve to its end.

Although more data are needed to have more detailed prevision, these models could help in predicting future confirmed cases if the spread of the virus do not change very strange. As we know, this virus is novel and have the ability to be transmitted easily. This can affect all the predictions, but to the best of our knowledge and for the time of writing, these models are the best. Investigating their protocol in this control like quarantine should be in the first line of other countries' program.

\section{Conclusion}

This research work investigates the answer to the most important questions raised today: when will this pandemic end and is there a possibility for the second

Figure 6: The normal distribution is within 1 standard deviation $(\sigma)$ of the mean $(\mu)$. round in case of returning to daily routine life. Despite accelerated virus mutation and the nature of the dataset based on time and date, the work done try to reduce the variability of the data by taking only the dataset from WHO, and John Hopkins university. The results point to the likelihood that there will be a second rebound of the pandemic in a year time, if the current taken precautions are eased completely.

The advantages of this study are that it helps the governments in making decisions and planning now for the future, reduces anxiety and prepares the mentality of people for the next phases of the pandemic. Moreover, 


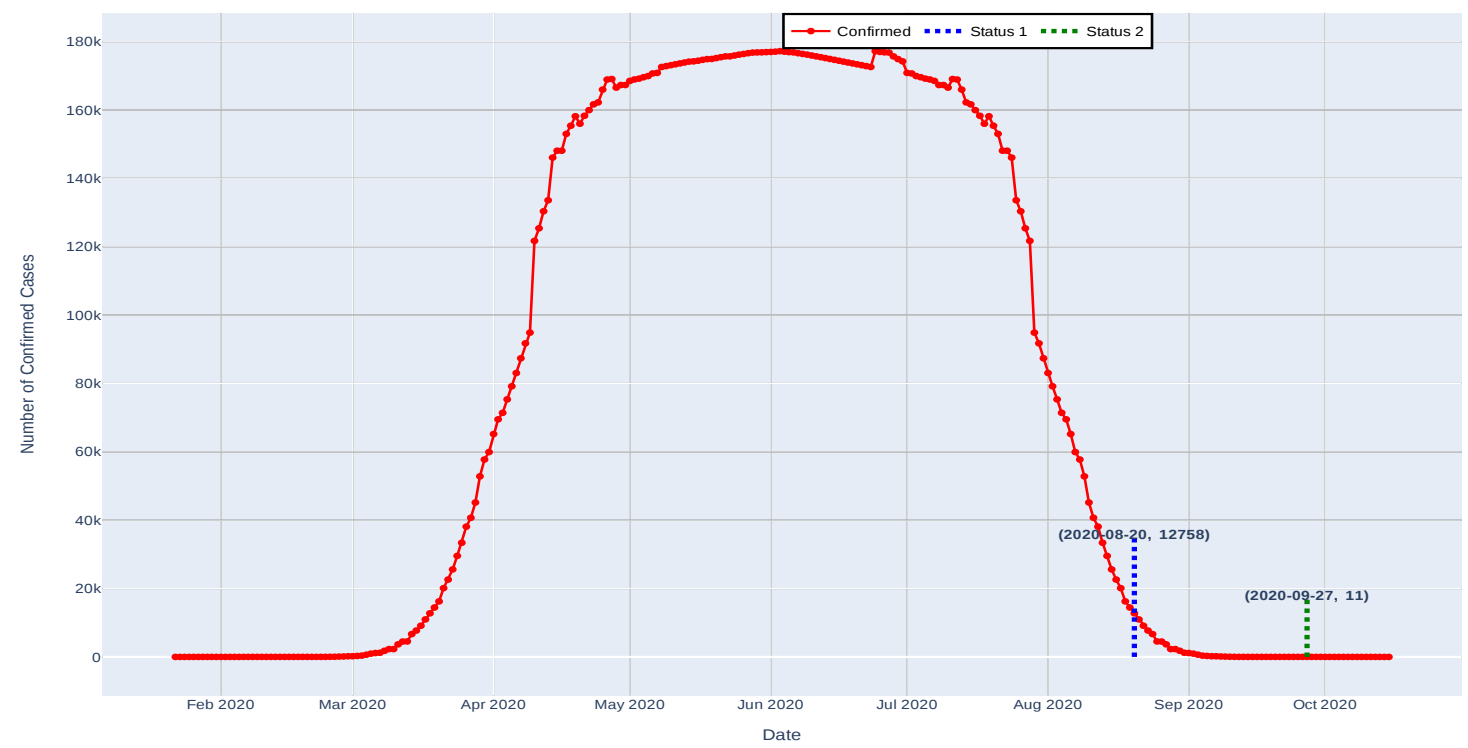

Figure 7: Expected Dead line for France with forecasting COVID-19.

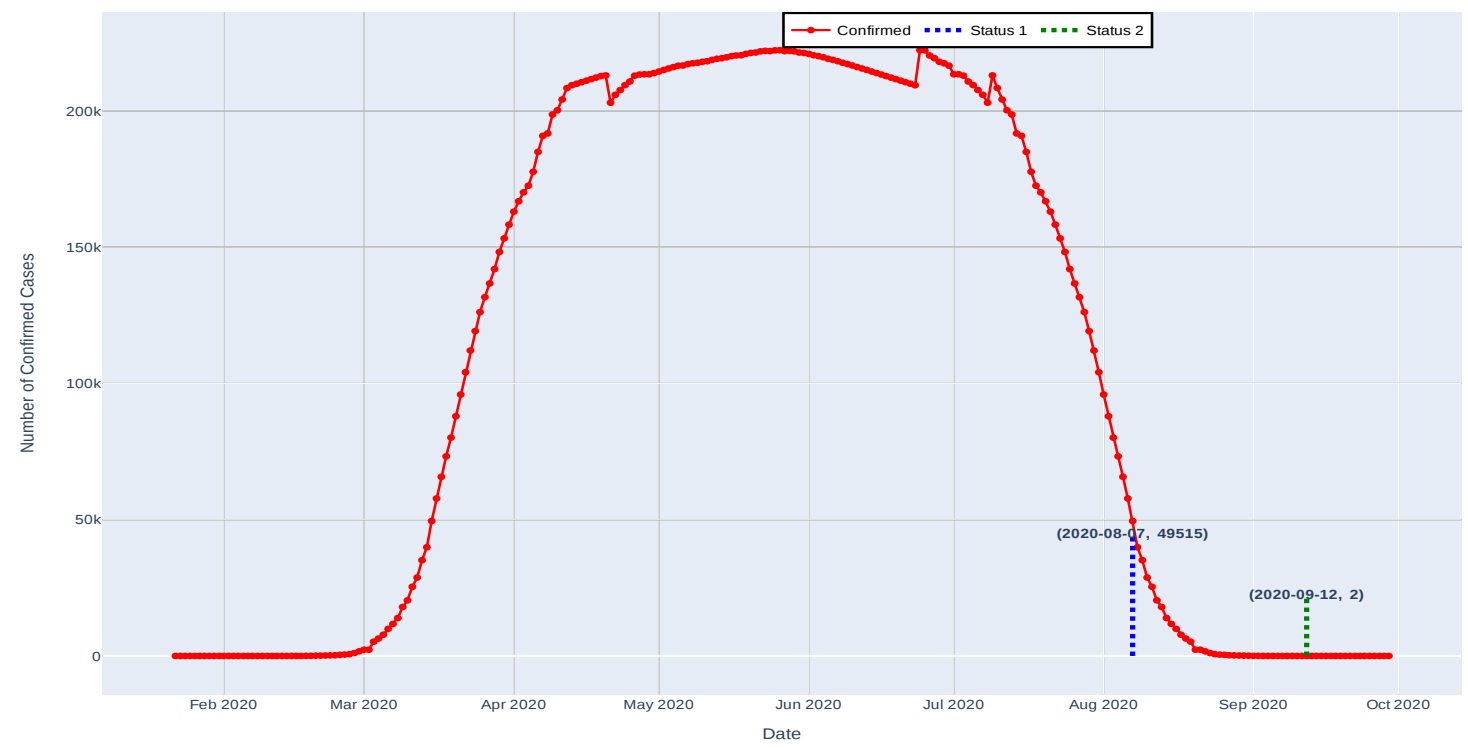

Figure 8: Expected Dead line for Spain with forecasting COVID-19.

our work clearly has some limitations. Nevertheless this we believe our work could be the a starting point that consider the uncertain nature of the ongoing COVID-19 pandemic and our growing inter-connected and complex world, what are eventually and fundamentally needed are the flexibility, robustness and resilience to deal with 


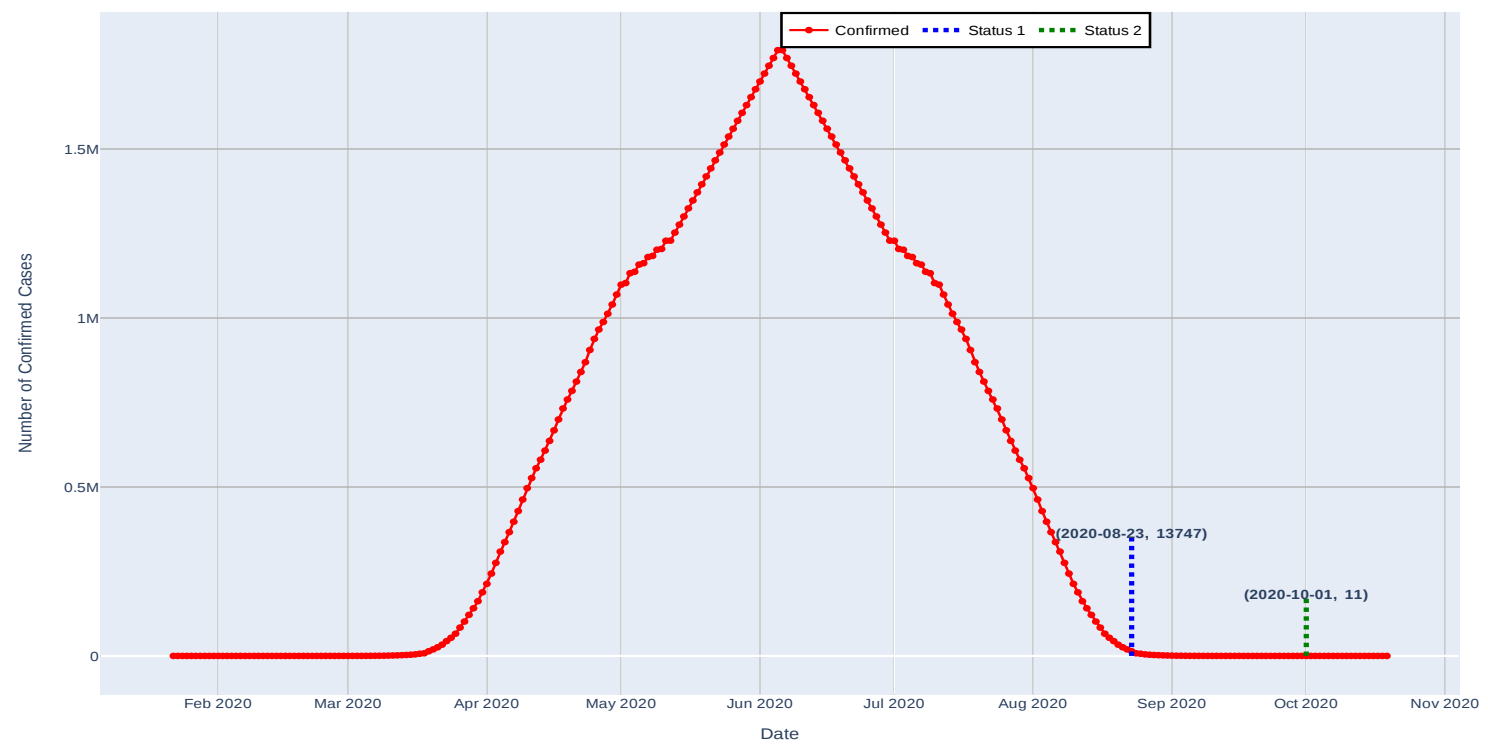

Figure 9: Expected Dead line for US with forecasting COVID-19.

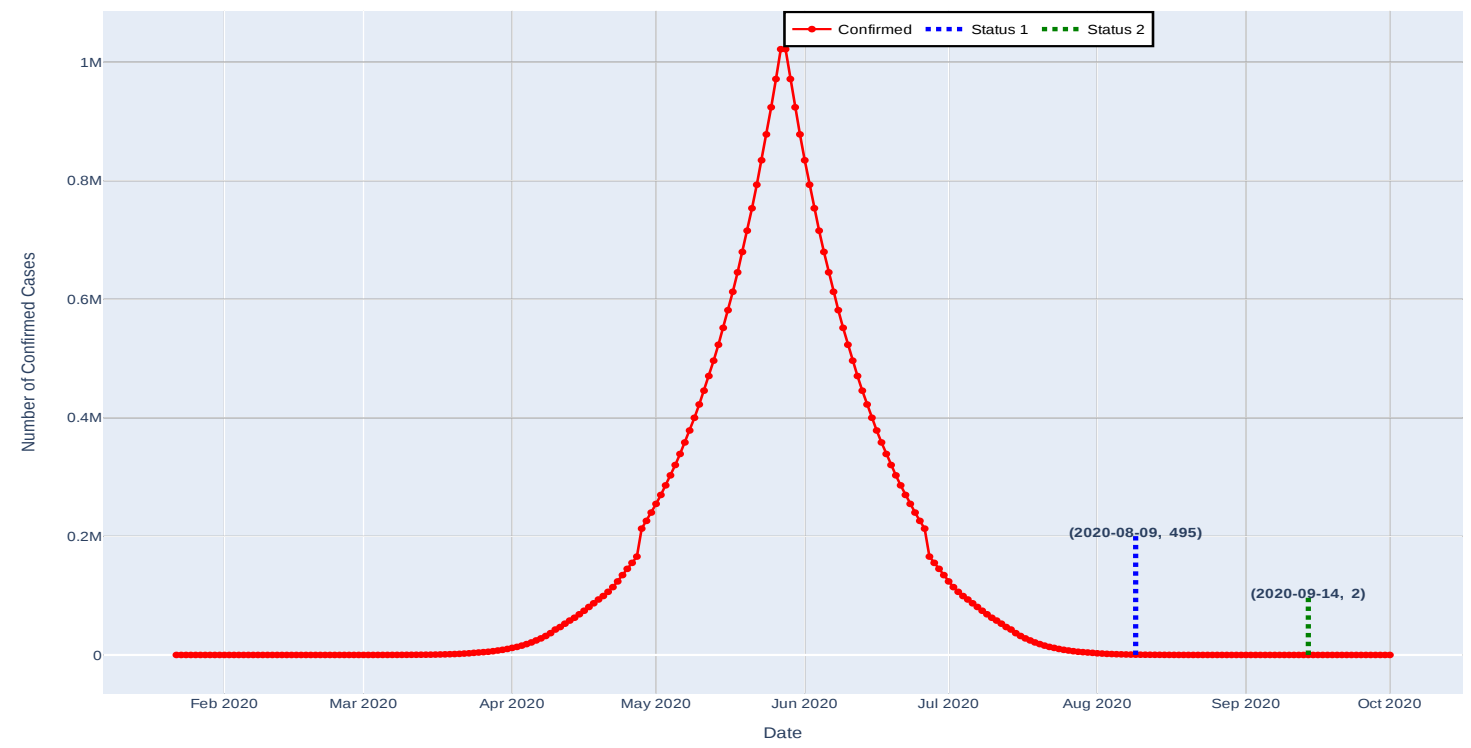

Figure 10: Expected Dead line for Russia with forecasting COVID-19.

unexpected future events and scenarios.

The future work of this research will focus on improving the performance of our model by using a huge data and apply the proposed model to many countries. Moreover, we plan to update this study with more analyses and cases, continually fine tune the prediction and 
Table 15: A comparison with the state-of-the-art models.

\begin{tabular}{|c|c|c|c|c|c|c|}
\hline \multirow{2}{*}{ Countries } & \multicolumn{3}{|c|}{ The state-of-the-art models [13] } & \multicolumn{3}{|c|}{ The proposed model } \\
\hline & Turning Date & End 99\% & End 100\% & Turning Date & End 99\% & End 100\% \\
\hline France & 3-Apr-20 & 18-May-20 & 5-Aug-20 & 01-Jan-2020 & 27-Sep-2020 & 13-Oct-2020 \\
\hline Italy & 29-Mar-20 & 21-May-20 & 25-Aug-20 & 08-Jan-2020 & 14-Sep-2020 & $01-$ Oct-2020 \\
\hline United States & $10-A p r-20$ & 24-May-20 & 27-Aug-20 & 30-May-2020 & $01-$ Oct-2020 & 15 -Oct-2020 \\
\hline Russia & 24-Apr-20 & 28-May-20 & 20-Jul-20 & 08-Jan-2020 & 14-Sep-2020 & $01-$ Oct-2020 \\
\hline United Kingdom & $12-$ Apr-20 & 27-May-20 & 14-Aug-20 & 08-Jan-2020 & 14-Sep-2020 & $01-$ Oct-2020 \\
\hline
\end{tabular}

visualization methodology.

\section{References}

[1] C.-C. Lai, T.-P. Shih, W.-C. Ko, H.-J. Tang, P.-R. Hsueh, Severe acute respiratory syndrome coronavirus 2 (SARS-CoV2) and coronavirus disease-2019 (COVID-19): The epidemic and the challenges, International Journal of Antimicrobial Agents 55 (2020) 105924. URL: https://doi.org/ 10.1016\%2Fj.ijantimicag. 2020.105924. doi:10.1016/ j.ijantimicag. 2020.105924.

[2] W. H. O. (WHO), Coronavirus, 2020 (accessed April 13, 2020). URL: https://www.who.int/health-topics/ coronavirus.

[3] W. H. O. (WHO), Rolling Updates on Coronavirus Disease (COVID-19)., 2020 (accessed April 15, 2020). URL: https://www. who.int/emergencies/diseases/novelcoronavirus-2019/events-as-they-happen.

[4] W. H. O. (WHO), Coronavirus Disease 2019 (COVID-19) Situation Report - 97. 2020., 2020 (accessed April 27, 2020). URL: https://www.who.int/docs/default-source/ coronaviruse/situation-reports/20200426-sitrep97-covid-19.pdf?sfvrsn=d1c3e800_6.

[5] H. Qiu, J. Wu, L. Hong, Y. Luo, Q. Song, D. Chen, Clinical and epidemiological features of 36 children with coronavirus disease 2019 (COVID-19) in zhejiang, china: an observational cohort study, The Lancet Infectious Diseases (2020). URL: https ://doi .org/10.1016\%2Fs1473-3099\% 2820\%2930198-5. doi:10.1016/s1473-3099(20)30198-5.

[6] J. Wu, J. Liu, X. Zhao, C. Liu, W. Wang, D. Wang, W. Xu, C. Zhang, J. Yu, B. Jiang, H. Cao, L. Li, Clinical characteristics of imported cases of coronavirus disease 2019 (COVID-19) in jiangsu province: A multicenter descriptive study, Clinical Infectious Diseases (2020). URL: https : //doi .org/10.1093\% 2Fcid\%2Fciaa199. doi:10.1093/cid/ciaa199.

[7] W. H. O. (WHO), Coronavirus, 2020 (accessed April 30, 2020). URL: https://www.who.int/health-topics/ coronavirus.

[8] Worldometer, COVID-19 CORONAVIRUS PANDEMIC, 2020 (accessed May 9, 2020). URL: https: //www. worldometers.info/coronavirus/.

[9] P. Yang, P. Liu, D. Li, D. Zhao, Corona virus disease 2019, a growing threat to children?, Journal of Infection (2020). URL: https ://doi.org/10.1016\%2Fj.jinf . 2020.02.024. doi:10.1016/j.jinf.2020.02.024.

[10] W. Cao, Z. Fang, G. Hou, M. Han, X. Xu, J. Dong, J. Zheng, The psychological impact of the COVID-19 epidemic on college students in china, Psychiatry Research 287 (2020) 112934. URL: https : //doi .org/10.1016\%2Fj . psychres.2020.112934. doi:10.1016/j.psychres. 2020 . 112934.
[11] C. S. Ho, C. Y. Chee, R. C. Ho, Mental health strategies to combat the psychological impact of covid-19 beyond paranoia and panic, Ann Acad Med Singapore 49 (2020) 1-3.

[12] C.-C. Lai, C.-Y. Wang, Y.-H. Wang, S.-C. Hsueh, W.-C. Ko, P.-R. Hsueh, Global epidemiology of coronavirus disease 2019 (COVID-19): disease incidence, daily cumulative index, mortality, and their association with country healthcare resources and economic status, International Journal of Antimicrobial Agents 55 (2020) 105946. URL: https://doi.org/ 10.1016\%2Fj.ijantimicag. 2020.105946. doi:10.1016/ j.ijantimicag. 2020.105946.

[13] J. Luo, Data-Driven Innovation Lab, When Will COVID-19 End? Data-Driven Prediction., 2020. URL: http://ddi. sutd.edu.sg.

[14] R. Dandekar, G. Barbastathis, Quantifying the effect of quarantine control in covid-19 infectious spread using machine learning, medRxiv (2020). URL: https://doi.org/10.1101\%2F2020.04.03.20052084. doi:10.1101/2020.04.03.20052084.

[15] C. J. Murray, Forecasting the impact of the first wave of the COVID-19 pandemic on hospital demand and deaths for the USA and european economic area countries, medRxiv (2020). URL: https://doi .org/10.1101\%2F2020.04.21. 20074732. doi:10.1101/2020.04.21.20074732.

[16] W. H. Organization, et al., Rational use of personal protective equipment for coronavirus disease (COVID-19): interim guidance, 27 February 2020, Technical Report, World Health Organization, 2020.

[17] L. Bayyurt, B. Bayyurt, Forecasting of COVID-19 cases and deaths using ARIMA models, medrxiv (2020). URL: https://doi.org/10.1101\%2F2020.04.17.20069237. doi:10.1101/2020.04.17.20069237.

[18] H. Tandon, P. Ranjan, T. Chakraborty, V. Suhag, Coronavirus (covid-19): Arima based time-series analysis to forecast near future, 2020. arXiv : 2004.07859.

[19] W. H. Organization, Report of the WHO-China Joint Mission on Coronavirus Disease 2019 (COVID-19)., 2020 (accessed Feb. 28, 2020). URL: https://www.who.int/docs/defaultsource/coronaviruse/who-china-joint-mission-oncovid-19-final-report.pdf.

[20] P. J. Brockwell, R. A. Davis, Introduction to time series and forecasting, springer, 2016.

[21] G. E. Box, G. M. Jenkins, G. C. Reinsel, G. M. Ljung, Time series analysis: forecasting and control, John Wiley \& Sons, 2015.

[22] M. S. Paolella, ARMA model identification, in: Linear Models and Time-Series Analysis, John Wiley \& Sons, Inc., 2018, pp. 405-442. URL: https://doi.org/10.1002\%2F9781119432036.ch9. doi:10.1002/9781119432036.ch9.

[23] Y. Al-Douri, H. Hamodi, J. Lundberg, Time series forecasting using a two-level multi-objective genetic algorithm: A case study of maintenance cost data for tunnel fans, Algorithms 11 
(2018) 123. URL: https://doi.org/10.3390/a11080123. doi:10.3390/a11080123.

[24] N. Chintalapudi, G. Battineni, F. Amenta, COVID-19 virus outbreak forecasting of registered and recovered cases after sixty day lockdown in italy: A data driven model approach, Journal of Microbiology, Immunology and Infection (2020). URL: https://doi.org/10.1016\%2Fj.jmii. 2020.04.004. doi:10.1016/j.jmii.2020.04.004.

[25] D. Ryabko, Asymptotic Nonparametric Statistical Analysis of Stationary Time Series, Springer International Publishing, 2019. URL: https ://doi.org/10.1007/978-3-03012564-6. doi:10.1007/978-3-030-12564-6.

[26] N. Eze, O. Asogwa, A. Obetta, K. Ojide, C. Okonkwo, A time series analysis of federal budgetary allocations to education sector in nigeria (1970-2018), American Journal of Applied Mathematics and Statistics 8 (2020) 1-8.

[27] G. Rebala, A. Ravi, S. Churiwala, An Introduction to Machine Learning, Springer, 2019

[28] P. Chen, A. Niu, D. Liu, W. Jiang, B. Ma, Time series forecasting of temperatures using SARIMA: An example from nanjing, IOP Conference Series: Materials Science and Engineering 394 (2018) 052024. URL: https : //doi.org/10.1088\% 2F $1757-899 x \% 2 F 394 \% 2 F 5 \% 2 F 052024$. doi:10.1088/1757$899 x / 394 / 5 / 052024$.

[29] J. K. Taubenberger, D. M. Morens, 1918 influenza: the mother of all pandemics, Emerging Infectious Diseases 12 (2006) 15-22. URL: https://doi.org/10.3201\%2Feid1209.050979. doi:10.3201/eid1209.05-0979.

[30] J. Guarner, Three emerging coronaviruses in two decades, American Journal of Clinical Pathology 153 (2020) 420-421. URL: https://doi.org/10.1093\%2Faj cp\%2Faqaa029. doi:10.1093/ajcp/aqaa029.

[31] C. Quan, W. Shi, Y. Yang, Y. Yang, X. Liu, W. Xu, H. Li, J. Li, Q. Wang, Z. Tong, G. Wong, C. Zhang, S. Ma, Z. Ma, G. Fu, Z. Zhang, Y. Huang, H. Song, L. Yang, W. J. Liu, Y. Liu, W. Liu, G. F. Gao, Y. Bi, New threats from h7n9 influenza virus: Spread and evolution of high- and low-pathogenicity variants with high genomic diversity in wave five, Journal of Virology 92 (2018) e00301-18. URL: https://doi.org/10. 1128\%2Fjvi.00301-18. doi:10.1128/jvi.00301-18.

[32] C. Contini, M. D. Nuzzo, N. Barp, A. Bonazza, R. D. Giorgio, M. Tognon, S. Rubino, The novel zoonotic COVID-19 pandemic: An expected global health concern, The Journal of Infection in Developing Countries 14 (2020) 254-264. URL: https://doi.org/10.3855\%2Fjidc.12671. doi:10.3855/ jidc. 12671 .

[33] Y. Yan, W. I. Shin, Y. X. Pang, Y. Meng, J. Lai, C. You, H. Zhao, E. Lester, T. Wu, C. H. Pang, The first 75 days of novel coronavirus (SARS-CoV-2) outbreak: Recent advances, prevention, and treatment, International Journal of Environmental Research and Public Health 17 (2020) 2323. URL: https://doi.org/10.3390\%2Fijerph17072323. doi:10. 3390/ijerph17072323.

[34] Y. Yan, L. Chang, L. Wang, Laboratory testing of SARSCoV, MERS-CoV, and SARS-CoV-2 (2019-nCoV): Current status, challenges, and countermeasures, Reviews in Medical Virology (2020). URL: https://doi .org/10.1002\%2Frmv . 2106. doi:10.1002/rmv. 2106.

\section{Declarations:}

The authors declare that there is no conflict of interest. 


\section{Figures}

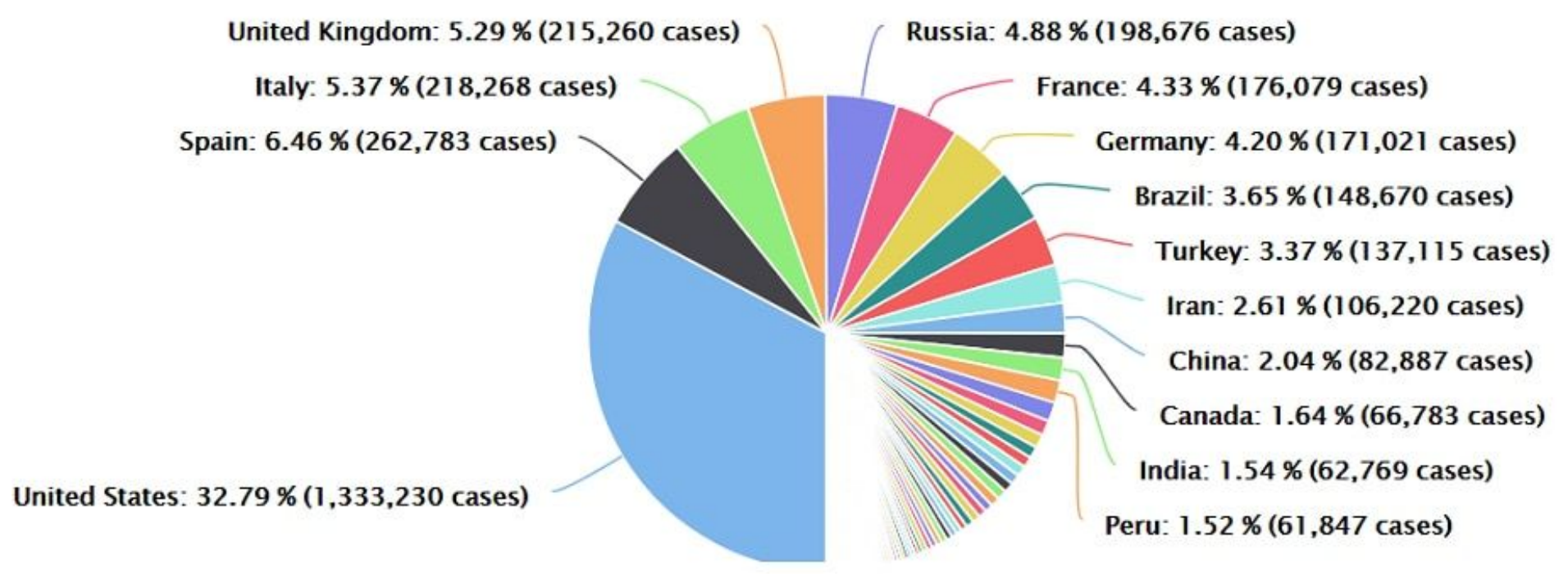

Figure 1

Distribution of cases as of May 9, 2020

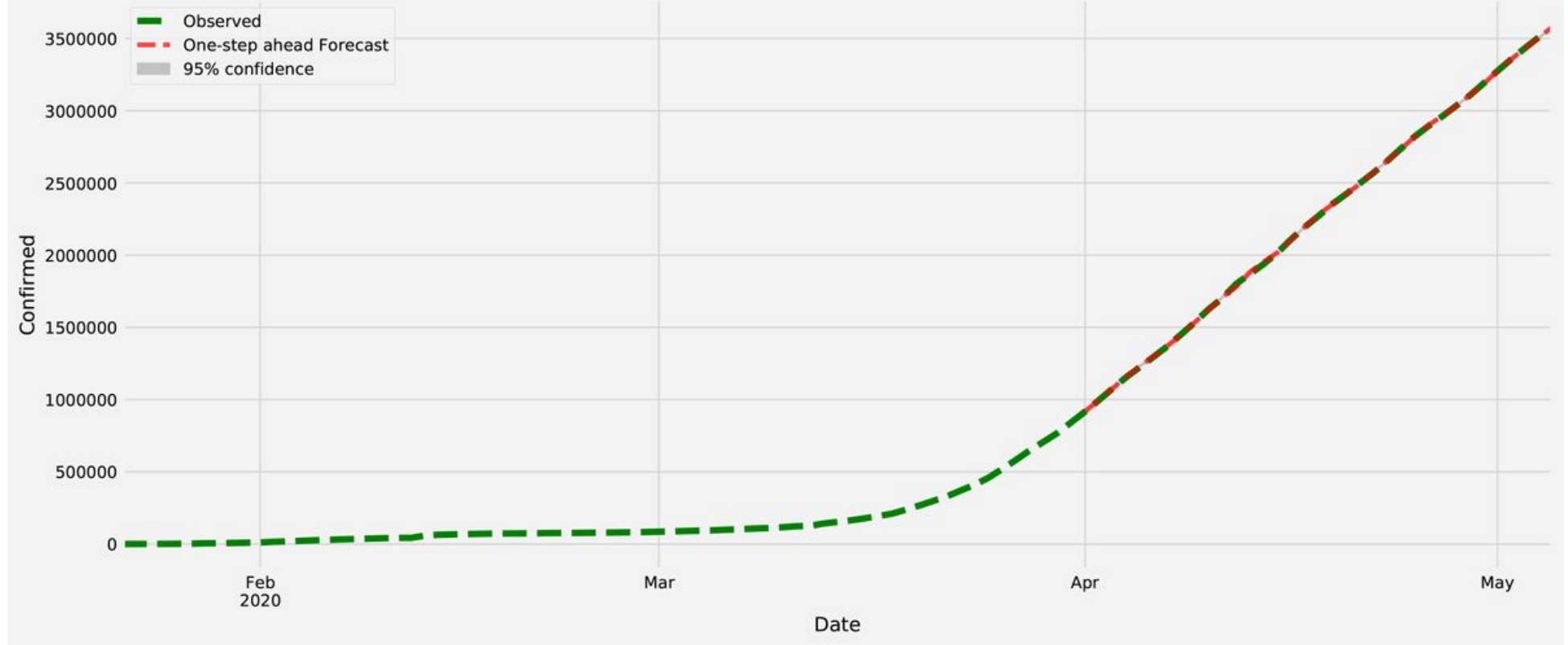

Figure 2

Comparison between the observed and predicted values (one-step ahead result) for SARIMA model on COVID-19 dataset. 


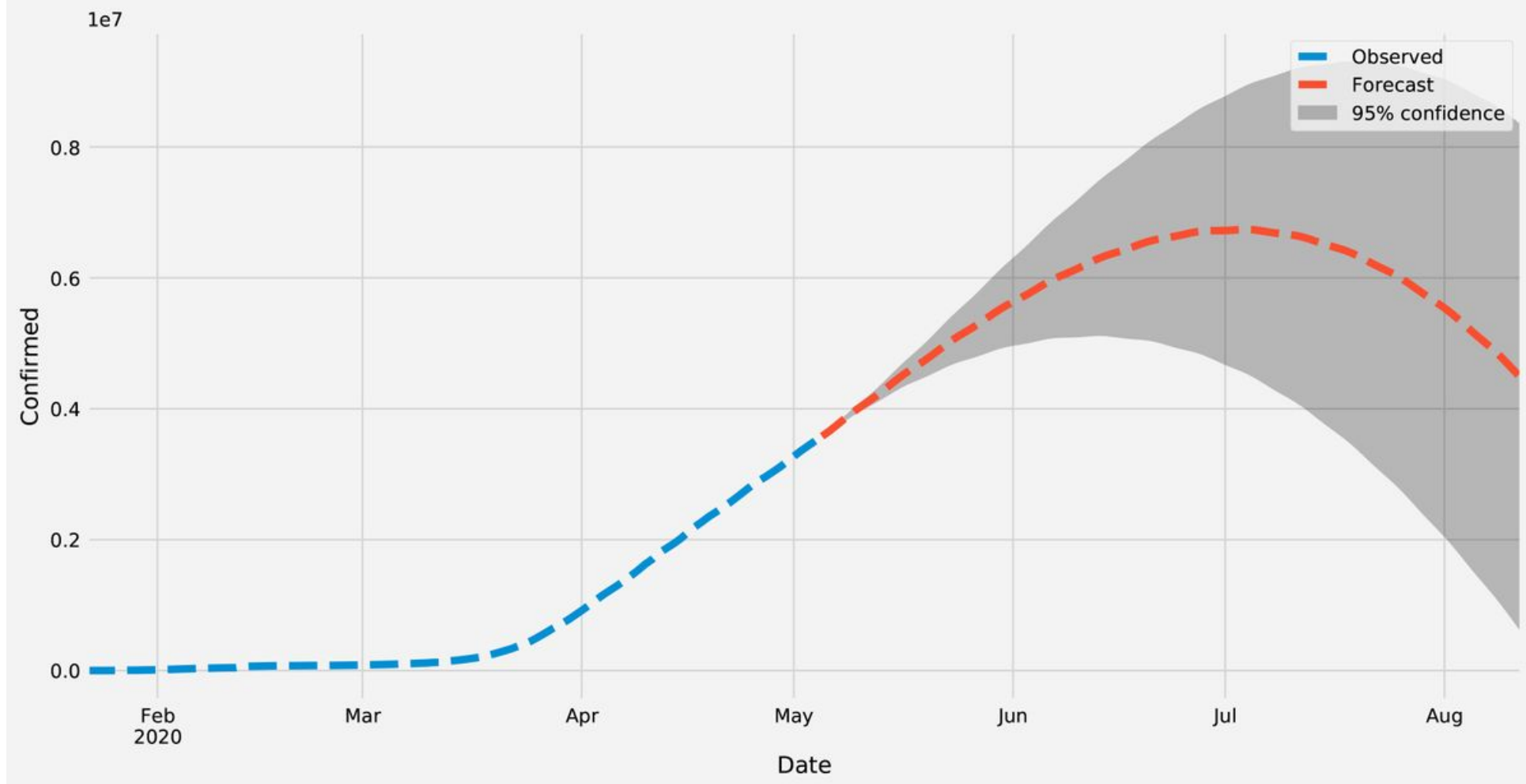

\section{Figure 3}

The forecasted values for the COVID-19 new cases over Globe until August 15, 2020.

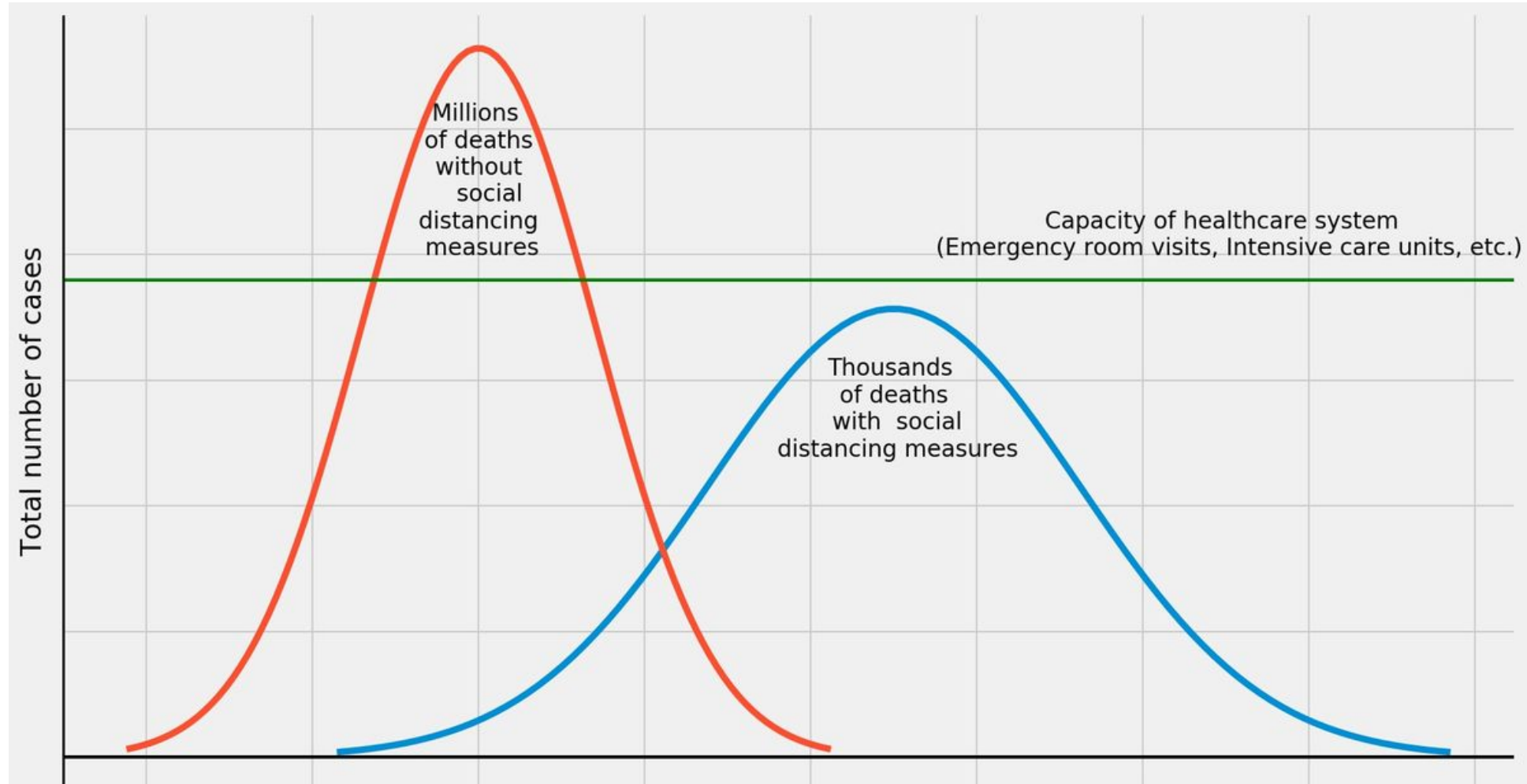

Time since the first confirmed case

\section{Figure 4}




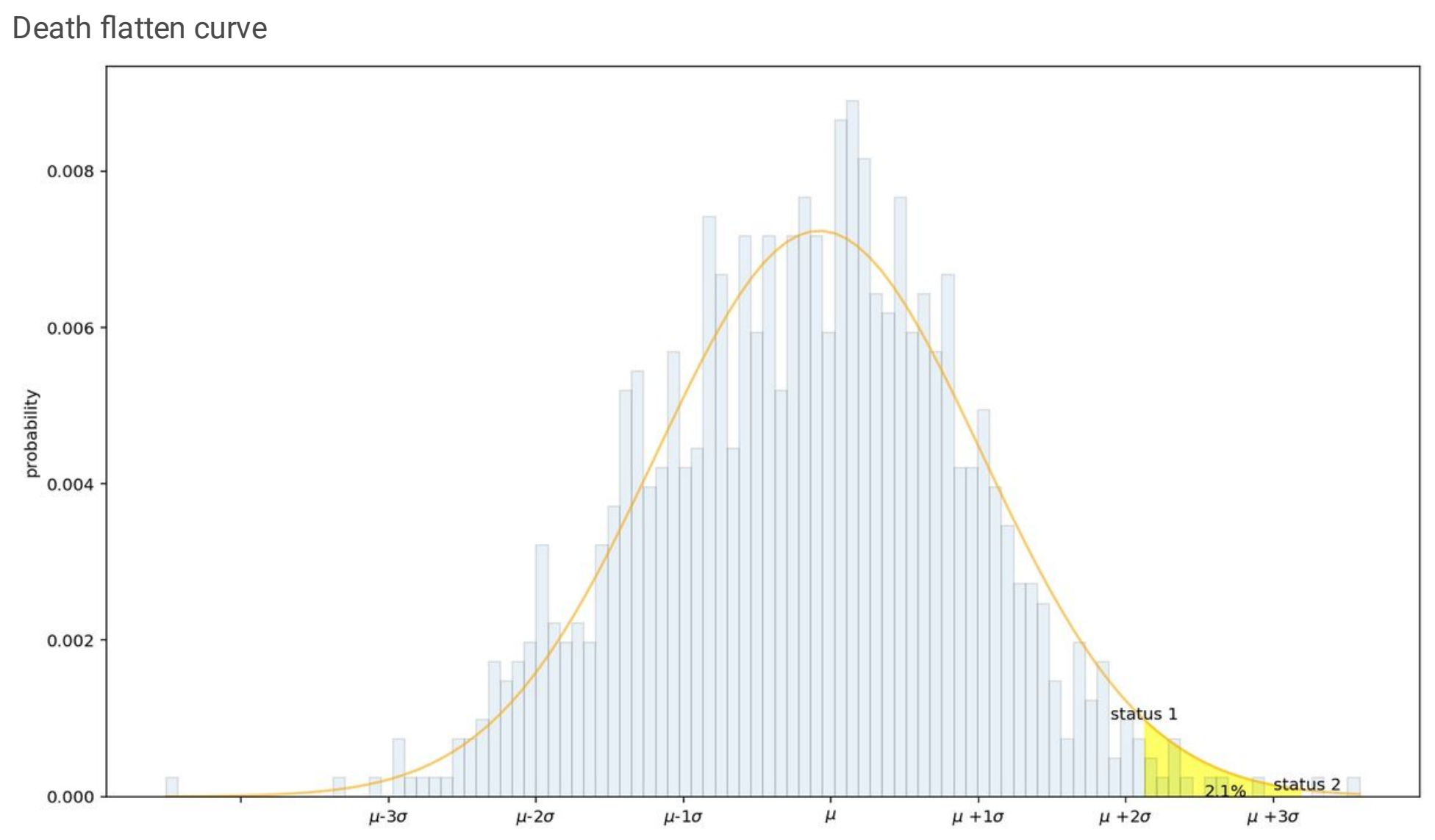

\section{Figure 5}

The normal distribution is within 1 standard deviation $(\sigma)$ of the mean $(\mu)$ using SARIMA. 


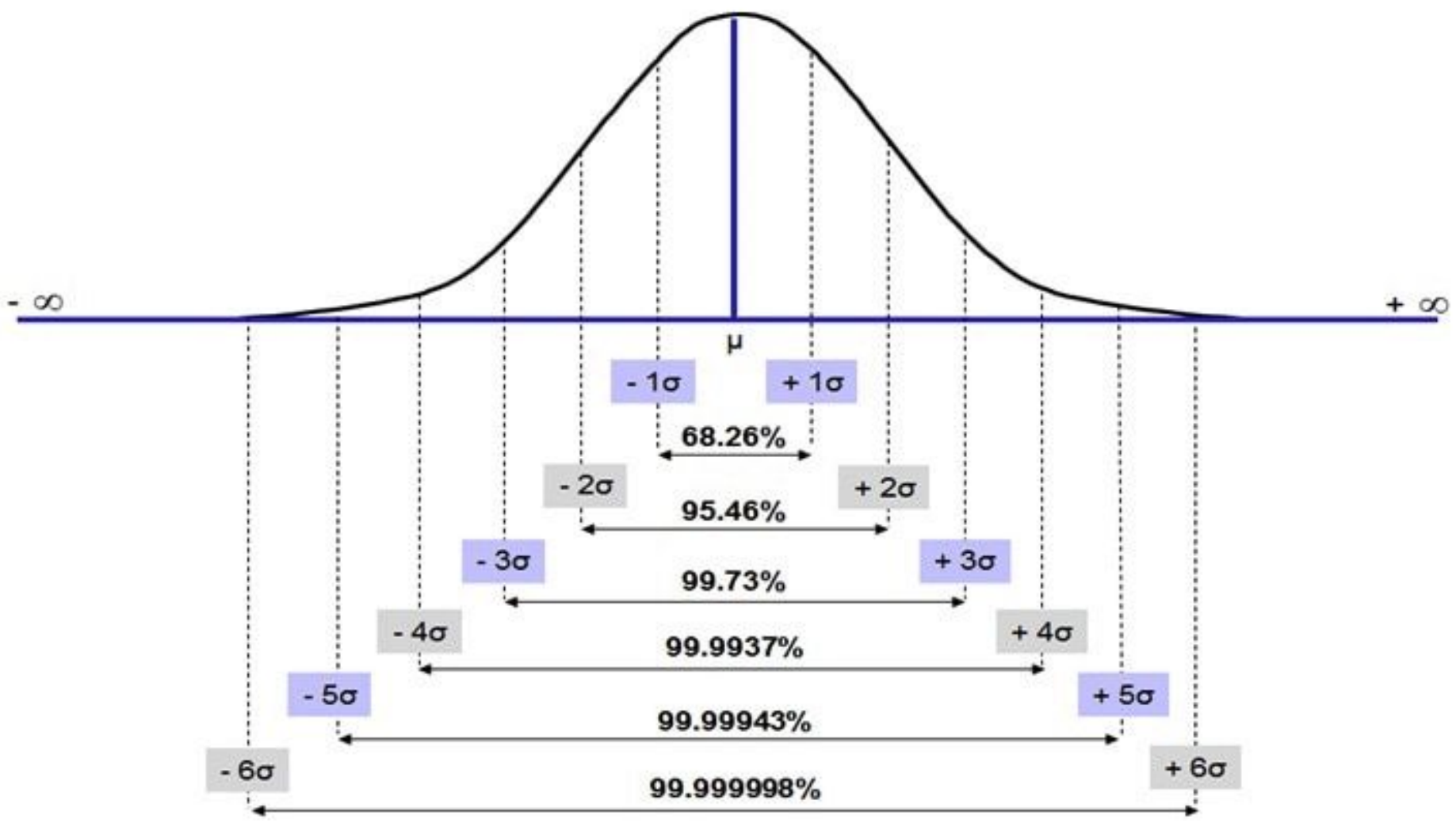

Figure 6

The normal distribution is within 1 standard deviation $(\sigma)$ of the mean $(\mu)$. 


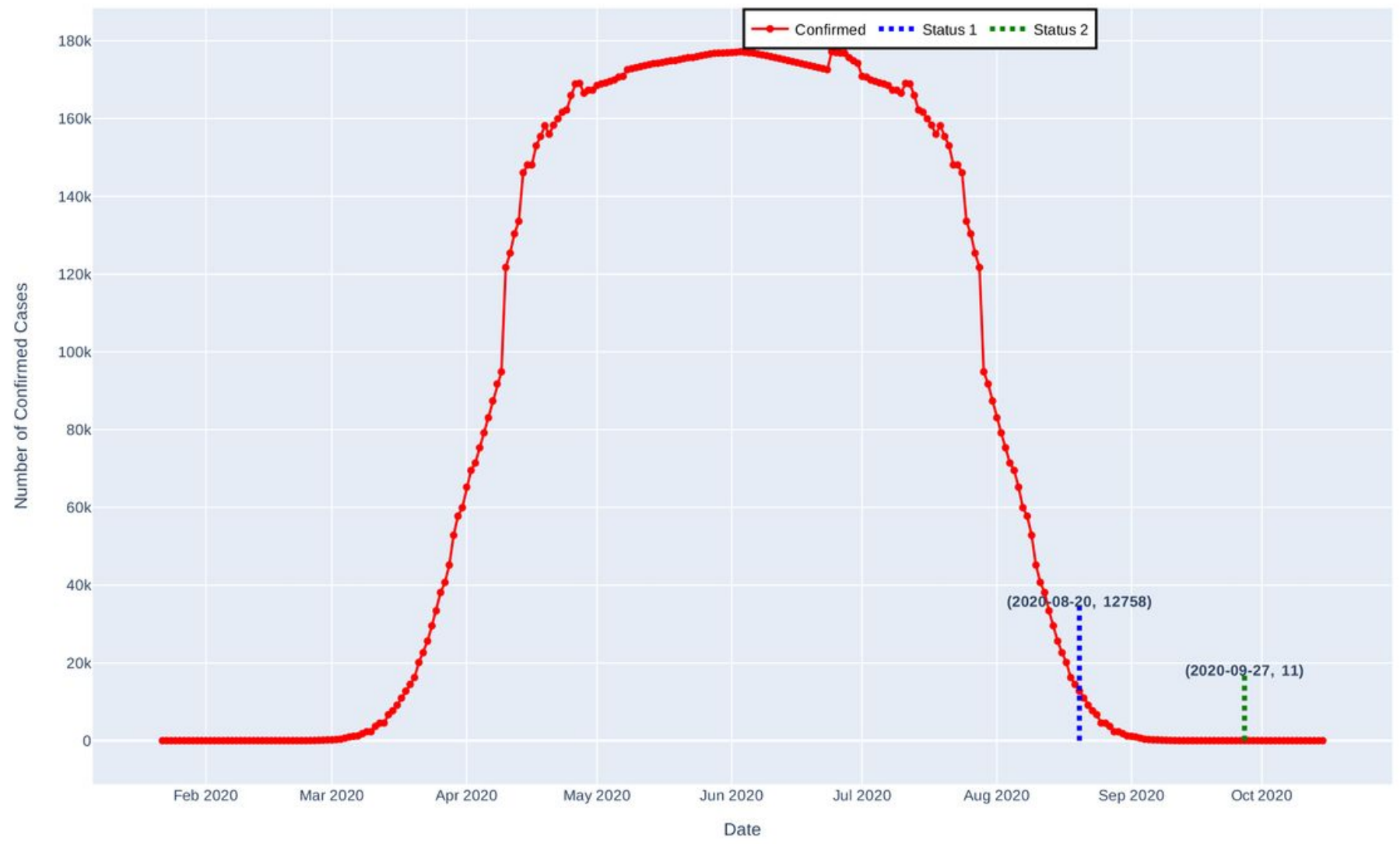

Figure 7

Expected Dead line for France with forecasting COVID-19. 


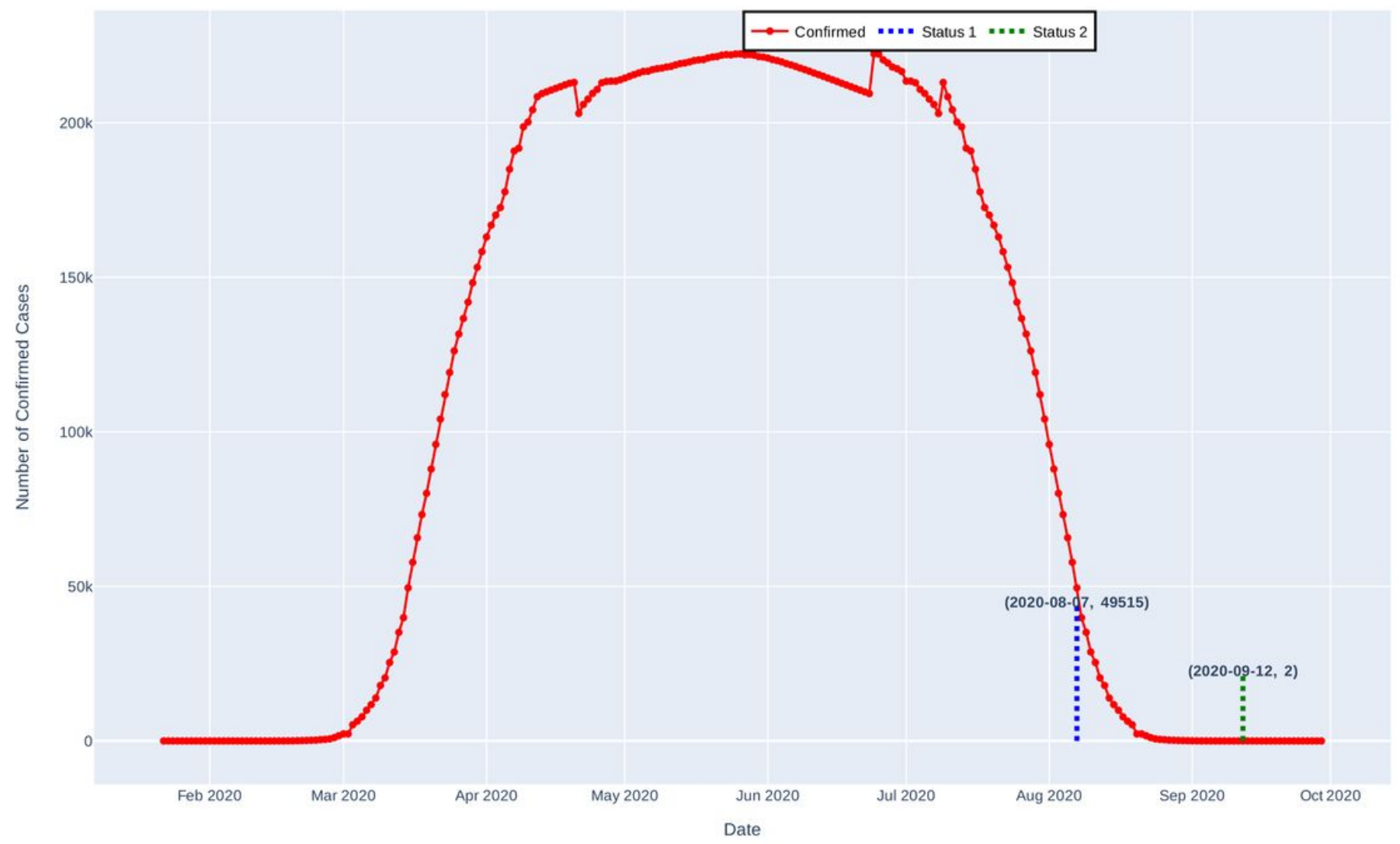

Figure 8

Expected Dead line for Spain with forecasting COVID-19 


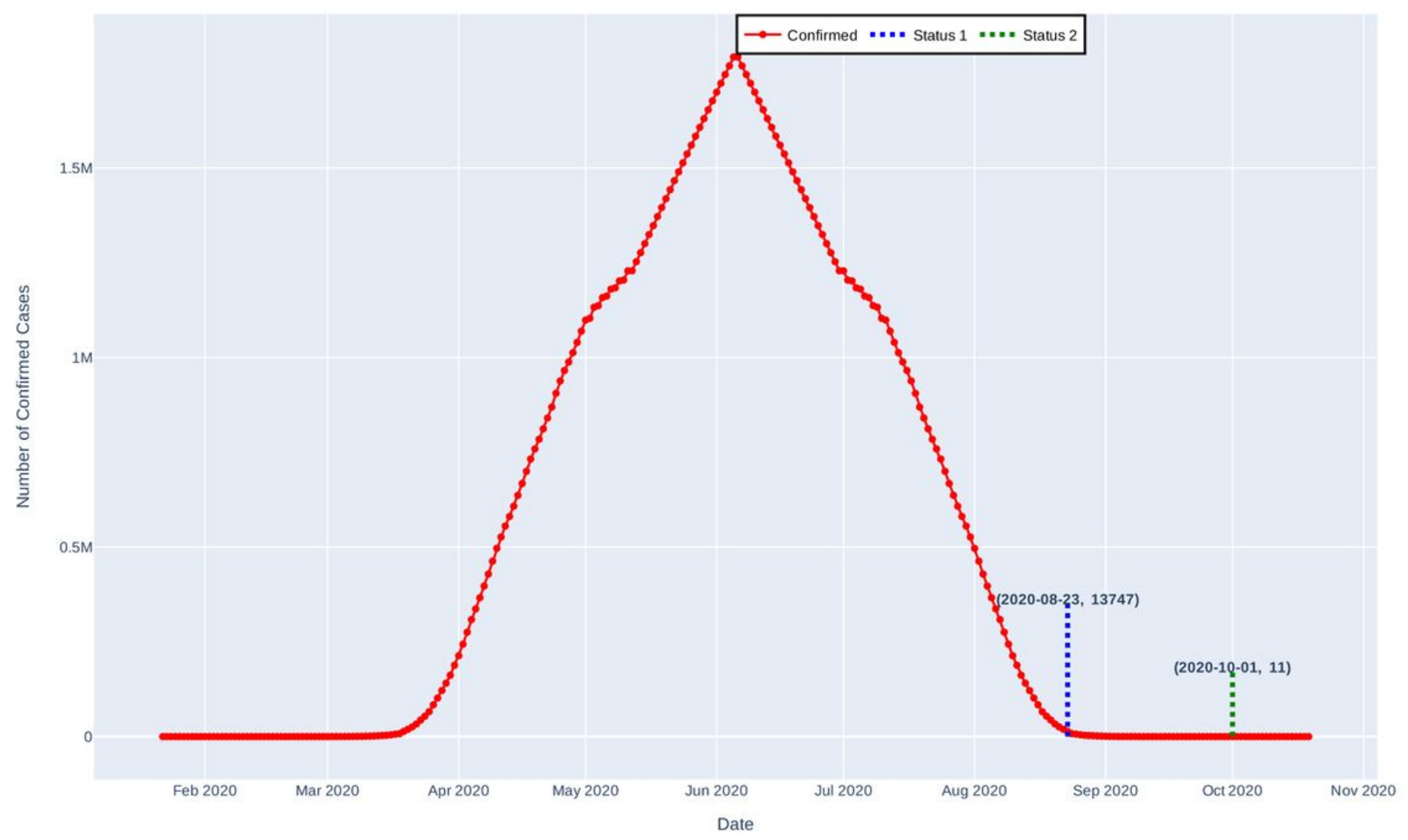

Figure 9

Expected Dead line for US with forecasting COVID-19 


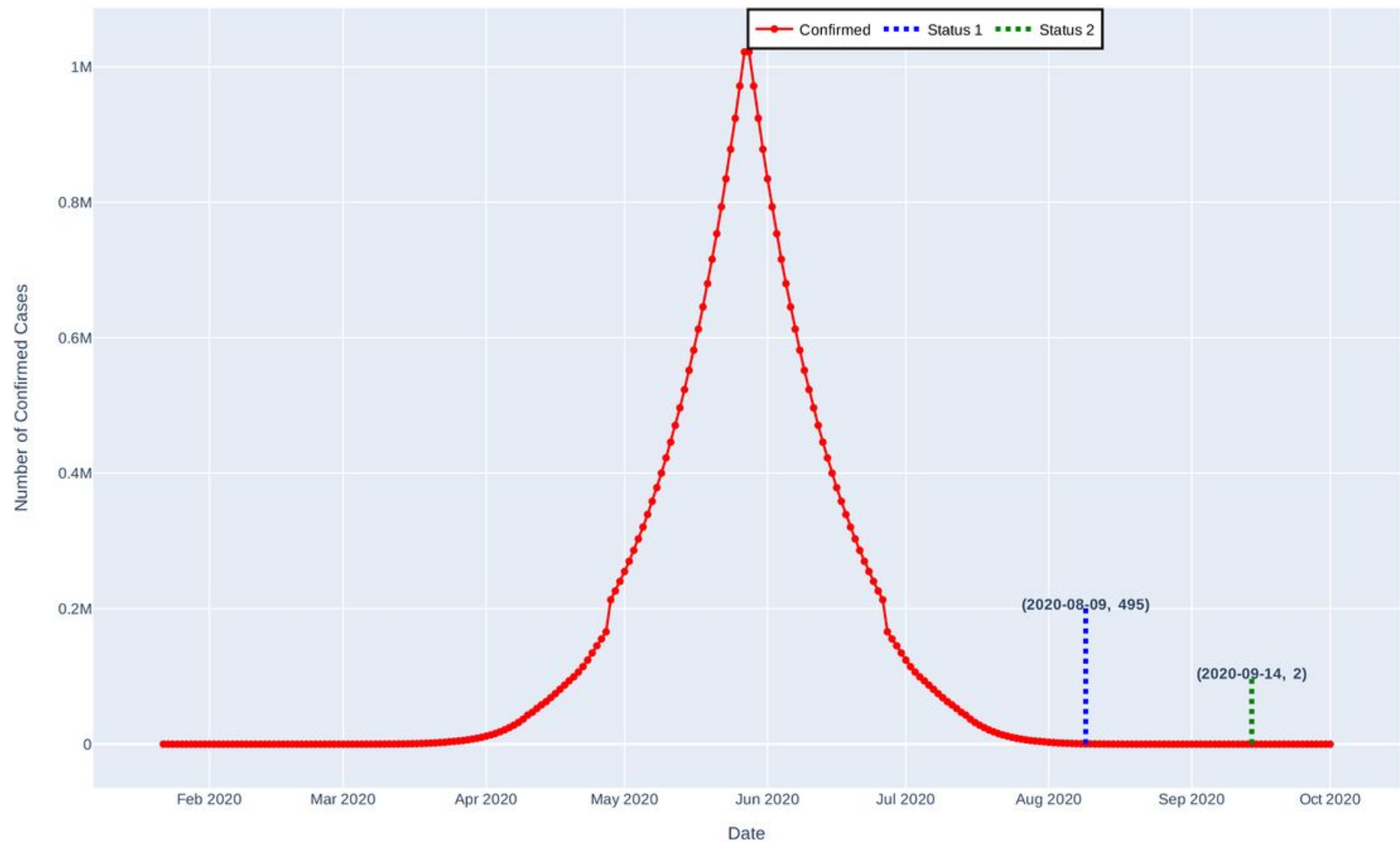

Figure 10

Expected Dead line for Russia with forecasting COVID-19

\section{Supplementary Files}

This is a list of supplementary files associated with this preprint. Click to download.

- Globaldata.xls 